\title{
Recent Advances in Methods for the Recovery of Carbon Nanominerals and Polyaromatic Hydrocarbons from Coal Fly Ash and Their Emerging Applications
}

\author{
Javed Alam ${ }^{1, *}$, Virendra Kumar Yadav ${ }^{2, *} \mathbb{D}^{\mathbb{D}}$, Krishna Kumar Yadav ${ }^{3}$, Marina MS Cabral-Pinto ${ }^{4, *} \mathbb{0}$, \\ Neha Tavker ${ }^{5}{ }^{\oplus}$, Nisha Choudhary ${ }^{5}$, Arun Kumar Shukla ${ }^{1}{ }^{\circledR}$, Fekri Abdulraqeb Ahmed Ali ${ }^{6}$, \\ Mansour Alhoshan ${ }^{1,6}$ and Ali Awadh Hamid ${ }^{6}$
}

check for

updates

Citation: Alam, J.; Yadav, V.K.; Yadav, K.K.; Cabral-Pinto, M.M.S.; Tavker, N.; Choudhary, N.; Shukla, A.K.; Ali, F.A.A.; Alhoshan, M.; Hamid, A.A. Recent Advances in Methods for the Recovery of Carbon Nanominerals and Polyaromatic Hydrocarbons from Coal Fly Ash and Their Emerging Applications. Crystals 2021, 11, 88. https://doi.org/ $10.3390 /$ cryst11020088

Academic Editor: Maged F. Bekheet Received: 21 December 2020

Accepted: 14 January 2021

Published: 21 January 202

Publisher's Note: MDPI stays neutral with regard to jurisdictional claims in published maps and institutional affiliations.

Copyright: (C) 2021 by the authors. Licensee MDPI, Basel, Switzerland. This article is an open access article distributed under the terms and conditions of the Creative Commons Attribution (CC BY) license (https:// creativecommons.org/licenses/by/ $4.0 /)$
1 King Abdullah Institute for Nanotechnology, King Saud University, P.O. Box-2455, Riyadh 11451, Saudi Arabia; ashukla@ksu.edu.sa (A.K.S.); mhoshan@ksu.edu.sa (M.A.)

2 School of Lifesciences, Jaipur National University, Jaipur 302017, India

3 Institute of Environment and Development Studies, Bundelkhand University, Kanpur Road, Jhansi 284128, India; envirokrishna@gmail.com

4 Geobiotec Research Centre, Department of Geosciences, University of Aveiro, 3810-193 Aveiro, Portugal

5 School of Nanosciences, Central University of Gujarat, Gandhinagar, Gujarat 382030, India; tavker.gini@gmail.com (N.T.); nishanaseer03@gmail.com (N.C.)

6 Chemical Engineering Department, College of Engineering, King Saud University, P.O. Box-2455, Riyadh 11451, Saudi Arabia; falhulidy@ksu.edu.sa (F.A.A.A.); alih6624@gmail.com (A.A.H.)

* Correspondence: javaalam@ksu.edu.sa (J.A.); virendra.yadav@jnujaipur.ac.in (V.K.Y.); marinacp@ua.pt (M.M.S.C.-P.)

Abstract: Coal fly ash is found to be one of the key pollutants worldwide due to its toxic heavy metal content. However, due to advancements in technology, coal fly ash has gained importance in various emerging fields. They are rich sources of carbonaceous particles which remain unburnt during burning of various coals in thermal power plants (TPPs). Various carbonaceous nanoparticles in the form of fullerenes, soot, and carbon nanotubes could be recovered from coal fly ash by applying trending techniques. Moreover, coal fly ash is comprised of rich sources of organic carbons such as polycyclic and polyaromatic hydrocarbons that are used in various industries for the development of carbon-derived value-added materials and nanocomposites. Here, we focus on all the types of carbon nanominerals from coal fly ash with the latest techniques applied. Moreover, we also emphasize the recovery of organic carbons in polyaromatic (PAHs) and polycyclic hydrocarbons (PCHs) from coal fly ash (CFA). Finally, we try to elucidate the latest applications of such carbon particle in the industry.

Keywords: coal fly ash; carbon nanominerals (CNMs); carbonaceous particle; polyaromatic hydrocarbons; carbon onions

\section{Introduction}

Coal fly ash (CFA) is a complex material produced from the combustion of pulverized coal in thermal power plants during the production of electricity [1]. Due to its complexity, until now, nearly 316 minerals were found individually while 188 minerals were present in groups identified in various coal fly ash samples from different parts of the world [2,3]. CFA is a fine glass-like, spherical shaped powder, heterogeneous in nature and has sizes varying from 0.01 to 100 microns [1,4]. It is generally light colored and consists mostly of silt and clay-sized glass spherical particles which provide a consistency somewhat like that of talcum powder. It is one of the most familiar and widely used pozzolanic materials [5,6], with its two most important factors, minerals and composition, depending on the various factors applied during their handling. Therefore, there is a possibility that one sample of CFA may vary with respect to the next one depending on the source of coal used; on the various environmental conditions during burning and cleaning with pulverization; 
on the design, types, and operations in the power plant boiler unit; on the degree of coal manufacture, storage, and handling of the fly ash; on the additives used for facilitating burning of coal or improving precipitation performance; on the productivity of emission control devices; and on the prevalent climatic conditions [1,7]. The typical compositions of higher-grade coal-derived fly ashes have $\mathrm{SiO}_{2}, \mathrm{Al}_{2} \mathrm{O}_{3}$, and iron and calcium oxides with varied weights of carbon, as analyzed by the loss on ignition (LOI) [8]. Due to the presence of value-added minerals in CFA, it is widely applied in ceramics [9], construction, civil engineering, and geopolymers [4]. However, with the progress of technology every year, there is gradual and progressive increase in CFA utilization in India as per the data provided by the central energy authority of India (CEA 2020). Table 1 shows the detailed fly ash production and utilization in India from 2010-2011 to 2019-2020.

Table 1. Fly ash production and utilization in India during the last decade (2010-2011 to 2019-2020*).

\begin{tabular}{ccccccccccc}
\hline Descriptions & $\begin{array}{c}\mathbf{2 0 1 0 -} \\
\mathbf{2 0 1 1}\end{array}$ & $\begin{array}{c}\mathbf{2 0 1 1 -} \\
\mathbf{2 0 1 2}\end{array}$ & $\begin{array}{c}\mathbf{2 0 1 2 -} \\
\mathbf{2 0 1 3}\end{array}$ & $\begin{array}{c}\mathbf{2 0 1 3 -} \\
\mathbf{2 0 1 4}\end{array}$ & $\begin{array}{c}\mathbf{2 0 1 4 -} \\
\mathbf{2 0 1 5}\end{array}$ & $\begin{array}{c}\mathbf{2 0 1 5 -} \\
\mathbf{2 0 1 6}\end{array}$ & $\begin{array}{c}\mathbf{2 0 1 6 -} \\
\mathbf{2 0 1 7}\end{array}$ & $\begin{array}{c}\mathbf{2 0 1 7 -} \\
\mathbf{2 0 1 8}\end{array}$ & $\begin{array}{c}\mathbf{2 0 1 8 -} \\
\mathbf{2 0 1 9}\end{array}$ & $\begin{array}{c}\mathbf{2 0 1 9 -} \\
\mathbf{2 0 2 0}\end{array}$ \\
\hline $\begin{array}{c}\text { Fly ash } \\
\text { production }\end{array}$ & 131.09 & 145.42 & 163.56 & 172.87 & 184.14 & 176.74 & 169.25 & 196.44 & 217.04 & 226.13 \\
\hline $\begin{array}{c}\text { Fly ash } \\
\text { utilization }\end{array}$ & 73.13 & 85.05 & 100.37 & 99.62 & 102.54 & 107.77 & 107.10 & 131.87 & 168.40 & 187.81 \\
\hline$\%$ Utilization & 55.79 & 58.48 & 61.37 & 57.37 & 55.69 & 60.97 & 63.28 & 67.13 & 77.59 & 83.05 \\
\hline & & * Source: CEA (Central Electricity Authority) 2010 to 2020. & &
\end{tabular}

A major portion of CFA is used for manufacturing bricks, tiles, cements, panels, metallurgy, landfills, etc. It is also used for river embankments, civil engineering, geopolymers, zeolites, and other lightweight materials [1,10]. In the current year, 2019-2020, the total CFA production was 226.13 million ton (MTs), out of which 187.81 MTs were use, i.e., $83.05 \%$, while $17 \%$ was left unused, especially near fly ash ponds. Of the total fly ash used $(83.05 \%)$, in 2019-2020, about 4.69\%, i.e., 10.62 MTs, was used for land and mine-filling purposes while $9.46 \%$, i.e., 21.39 MTs, was used for manufacturing bricks and tiles and about $19.08 \%$, i.e., $43.14 \mathrm{MTs}$, was used for civil engineering purposes like for fly ash overs, roads, embankments, and dykes. Besides these, about $35.06 \mathrm{MTs}$, i.e., $15.50 \%$ CFA, were used for reclamation of low-lying areas; about $25.60 \%$, i.e., 57.88 MTs, CFA was used for the cement industry; and about $0.06 \%$, i.e., $0.14 \mathrm{MTs}$, CFA was used for agricultural purposes, especially in the form of fertilizers [4,11]. As far as developed countries are concerned, European countries like France have successfully achieved about 100 percent utilization of CFAs [12]. Among the South-Asian countries, China has nearly reached 100\% CFA utilization in the last few years.

Besides basic minerals, i.e., ferrous, silica, and alumina, CFAs are rich sources of carbon and polyaromatic hydrocarbons (PAHs) [13] which finds applications in many industries [14]. Currently, the carbon-based industries rely on several other industries to meet their demand of raw material. Therefore, CFAs could act as best substitutes for the recovery of both forms of carbon materials, i.e., organic and inorganic [15]. Both of these carbon sources are coal, present in the organic form. After combustion in a thermal power plant furnace, due to the reduced efficiency of a furnace, they are not completely burnt. Therefore, CFA can act as a potential raw material for carbon with several advantages including being economical, being eco-friendly, and minimizing solid waste arising due to CFA dumping in fly ash ponds [16].

\section{Importance of Carbon Nanomaterial and PAHs}

Nanoscience and nanotechnology being an interdisciplinary area of investigation offers several opportunities for scientists in diverse areas to explore the possibilities of novel research $[17,18]$. Several nanostructures have been formed and planned for use in altered systems and devices. Amongst them, these carbon nanostructures have received vast attention and have been extensively manufactured and inspected [19]. More recently, the science 
of carbon has gained great visibility with the discovery of fullerenes in 1985 along with the first high-resolution transmission scanning electron microscopy (HRTEM) observations of carbon nanotubes (CNTs) in 1991. The carbon nanomaterials (CNMs) have controlled porosity and surface chemistry, and superior thermal and mechanical features with an acceptable stability [20]. The arrival of nanotechnology, fullerene discovery in 1985, and the identification of carbon nanotubes (CNTs) in 1991 have boosted carbon chemistry. There is continuous increase in the importance of CNMs in science and technology, energy, environment, water, or biomedicine. They have excellent mechanical properties that can attract much attention for use in a variety of applications [21,22]. Moreover, their minute size, high surface-to-volume ratio (SVR), and electron-rich and lightweight properties make them a suitable material for nanotechnology-based applications [23]. Carbon nanostructured materials show different allotropes on the $0-, 1-, 2-$, and 3-dimensional nanoscales such as CNTs, nanocarbon coating, fullerene, graphene, and diamond or porous carbonaceous particles [24]. Moreover, carbon nanomaterials can have new applications for their physical, electrical, and chemical properties by clubbing with unlike functional nanomaterials, such as CNT nanocomposites with functional NPs, metal or oxide nanomaterials and carbon nanocoatings with functional metallic particles, or graphene modified with carbonaceous particles [25]. Carbon-rich solid waste, like high carbon CFA; agricultural waste [14]; and other industrial waste have been rarely utilized as a source for nanomaterial production.

\section{Polycyclic Aromatic Hydrocarbons (PAHs) Presence in CFA}

PAHs are a huge group of ubiquitous chemicals possessing higher than 100 organic compounds comprised of two or more fused C-rings derived from benzene $[26,27]$. The formation takes place at the time of incomplete combustion of coal in coal-fired TPPs. Moreover, PAHs can also be generated from oil, garbage, gas, and organic substances like tobacco or charbroiled meat [26]. PAHs can be synthesized by both natural and anthropogenic methods. The natural synthesis method includes volcanic content and forest fires, while the anthropogenic method includes industries, internal combustion, and incomplete or partially burned fossil fuel and, through exhausts, diesel engine, aviation, and cigarette smoke. Fossil fuels like coal combustion are one of the major source of PAHs [28]; apart from this, it is also present in soil, water surface and ground water, air, and sediment.

\section{CFA as a Natural Source of Carbon Nanomaterials (CNMs) and PAHs}

\subsection{CFA as a Natural Source of CNMs}

The carbonaceous elements of CFA are usually termed unburnt carbon particles or chars, which are made up of porous char particles and aggregated submicron particles [29]. These carbon nanoparticles are basically carbon which is unable to burn during the burning of pulverized coal in TPPs. Some of the unburnt carbon (UC) residues are collected with the CFA in the precipitators [30], which can be precisely and appropriately identified with the use of HRTEM. The parent source of CFA is coal, which is a rich source of carbon [31]. Generally, coals of higher grades (like anthracite and bituminous) have higher percentages of carbon. The CFA, which has a higher amount of UC, is generally known as high carbon fly ash (HCFA) [32-34]. Based on the carbon content, CFA can be further classified into three classes, i.e., low or ultralow, moderately high, and very high carbon ash [35]. The percentage of UC in CFA mainly varies from $2-12 \%$, but it could be more than $20 \%$ and, in exceptional cases, could reach up to $57 \%$ [29]. Therefore, considering an average $1-12 \%$ carbon content in CFA, there is around 8-96 MTs of carbon residues annually around the world (IEA, 2017) [36]. However, there are several other factors that affect the composition of carbon in the CFA. The factors affecting UC value in the CFA could be categorized within two main groups-the effect of coal characteristics (e.g., mineral matter, type of coal, their particle size, presence of moisture, maceral composition, calorific value (CV), and volatile matter) and the consequence of the design of a combustion system and their operating conditions (e.g., residence time available for burning in furnace, furnace heating 
loading, oxygen feed, temperature and pressure of the boiler, air/coal ratio, flow rate of heat, and pattern of flame) [37,38]. Unlike sub-bituminous coal, bituminous-coal-derived CFA includes both amorphous as well as crystalline carbons that bind together other CFA particles [31,39].

The coal undergoes pyrolysis, during which the carbon sources are burned and there is formation of new minerals at a desired temperature [40]. The ash is left with the unburned carbons due to incomplete burning of the coal. This unburnt carbon in CFA is considered an undesired material for civil engineering [41]. For use in cements, tiles, bricks, roads, etc., the carbon must be eliminated and should be brought to the desired range [1], while the removed carbon can be utilized either directly or after purification in place of carbon materials as an adsorbent, as fuel, or as a precursor for the synthesis of carbon-based nanomaterial $[37,42]$. Such applications of carbon particles from waste CFA will reduce the problem not only related to CFA but also of an alternative source of carbon and carbon-based nanomaterials. The UC in the CFA produced from low-NOx pulverized coal combustion revealed that these are the mixtures of soot and coal char. The UC or carbon particles of CFA are always accompanied by traces of elements like $\mathrm{Si}, \mathrm{Al}, \mathrm{Hg}$, Se, $\mathrm{Fe}$, and others $[1,43,44]$. Such carbon particles require HRTEM for suitable identification and material information.

\subsection{Coal Fly Ash as a Source Material of PAHs}

The 3-D network of coal is comprised of condensed aromatic and hydroaromatic compounds that are allied by short alkyl bridges and linkages of ether and thioether. Moreover, such 3-D structures of coal also possess PAHs as an integral part $[45,46]$. The organic content of coal includes complementary structures, where the major constituent is a macromolecular, non-soluble, 3-D network with condensed aromatic and hydroaromatic units which in turn are joined by ether and thio-ether linkages (like methylenes) [47], while the other fraction is a molecular phase of compounds in which the molecular mass is in the ranger of low to medium. Such compounds can be typically solubilized in the organic solvents with varying dispersals of aliphatic and several type of aromatic hydrocarbons like hydroxylated polycyclic aromatic compounds, polycyclic aromatic, and hydroaromatic hydrocarbons. [48]. In comparison to the bottom fly ash or CFA, their parent molecule, i.e., coal, has a higher content of total PAHs. The PAH concentration in coal may fall in the range of up to $100-1000$ of $\mathrm{mg} / \mathrm{kg}$ based on the coal ranking and its higher values especially for hard coals [49,50].

There are two ways for PAHs to be emitted into the surrounding from a combustion source [26]. PAHs are bound to release into the atmosphere mainly in the vapor phases directly arising from the combustion facility. PAHs could also be released along with the solid phases (CFA or bed ash), from where they could be either evaporated or dissipated into the surrounding environment [51]. The PAH percentage in CFA mainly depends on the type of coal or fuel used, the technology applied for the burning of coal, and the residence time of ash inside the combustion facility [52].

\section{Estimation of Carbon Content in CFA}

The estimation of UC in any compound like CFA can be easily carried out by a LOI at higher temperature [53]. This LOI acts as an indicator for the UC content of CFA. In order to utilize the class F or class $\mathrm{C}$ coal fly ash for concrete purposes, it has to be nearly $6 \%$ LOI [54]. However, it is very difficult to report whether the LOI under high temperature is either due to the UC or due to the breakdown of various chemical bonds in the different mineral phases present in CFA. In addition to these two factors, sometimes the LOI is also caused by the moisture adsorbed physically on the surface of the molecule $[55,56]$. In addition to this LOI-based conventional technique for the UC estimation, there are a few other techniques, i.e., thermogravimetric analysis (TGA) [57] and elemental analysis techniques [58]. Both of these techniques are more precise than the LOI-based conventional method for UC estimation in the CFA. The only problem associated with the TGA and 
elemental analysis techniques is that, along with UC, some inorganic carbon in the form of carbonates are frequently encountered in UC estimation [15,59]. Valeev et al., 2019, reported an accurate and advanced method for the estimation of carbon contents in the CFA. In this technique, carbon content was analyzed by a fractional gas analyzer CS-600 (LECO Corporation, USA). The CFA samples of about $1 \mathrm{~g}$ were kept in ceramic crucibles and then placed into an induction furnace. Finally, the $C$ concentrations were analyzed by infrared absorption of carbon dioxide present in the gas phase during burning of the sample in the surplus oxygen atmosphere [60,61]. There are also some new emerging techniques like carbon, hydrogen, nitrogen, and sulfur (CHNS) element analyzer; Electron diffraction spectroscopy (EDS); Total organic carbon (TOC) analyzer; x-ray photoelectron spectroscopy (XPS); and electron scattering chemical analysis (ESCA), which could be more promising for the estimation of UC from the CFA [62].

\section{Recovery of Carbon Nanomaterial from CFA}

CFA nanomaterial containing $C$ can be improved either by dry or wet-based methods such as electrostatic separation, froth flotation, separation based on density, and a few more $[63,64]$. The various methods that are used for carbon recovery or UC from CFA are depicted below in schematic Figure 1, and their summarized form is given in Table 2.

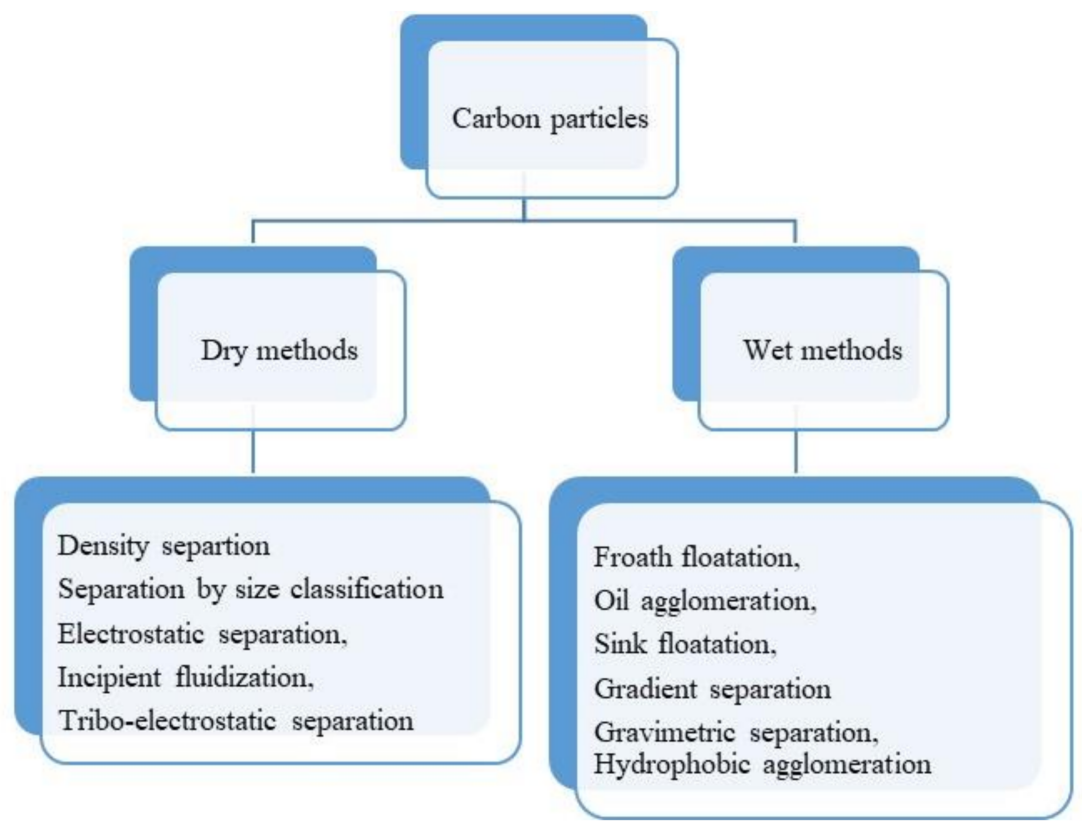

Figure 1. Methods of carbon separation from coal fly ash (CFA).

\subsection{Wet Separation Method \\ 6.1.1. Froth Flotation (FF)}

Among the wet separation methods, FF is one of the most reliable and economical technique for the extraction of UC or carbon particles from CFA $[64,65]$. The extraction of UC from CFA by FF applies a sequential separation step which has to be further separated. In FF, the efficiency of UC separation from CFA depends on the granulator separation of UC [66]. It is based on the separation of hydrophobic materials from hydrophilic materials [67]. The maximum UC can be extracted when separation is carried out from the carbon-rich fraction, whereas efficiency is poor if the char particles are evenly distributed in the CFA irrespective of their size. The simplicity and exclusion of other liquid media makes the FF technique quite reliable and simple. The FF technique relies on adhering the property of air bubbles onto the external surface of the specific particles [68]. By applying the FF technique, the carbon particles or UCs adhere to the surface of the air bubbles and are removed in an agitated tank, leaving behind the hydrophilic residual mineral particles 
present in the CFA. Reagents or additives that are applied in column flotation are pine oil (as frother), kerosene or foam (as collector), butanol (as a promoter which increases the flotation capacity of the carbonaceous particles/typically buoyancy of carbon particles), and methyl isobutyl carbinol or sodium meta-silicate (as a dispersant/depressant) [69-71]. However, based on the consideration of clear contrast between the properties of interface and UC and CFA particles, FF is thus the most reliable and desirable technique for the separation of $C$ from CFA. Various research in the literature are available where the FF technique is applied for the extraction of combustibles from CFA materials [70,72]. One such work was reported by Wu et al., 2020, where UCs were separated from CFA by FF, showing that the UC particles could be characterized by the bubble-particle attachment angle (BPAA), which is susceptible to the various operating parameters $[73,74]$.

The progressive technique of froth flotation in a flotation column is a cyclonic circulation method. There are a few positive points about the column: it requires little energy, less space for equipment, and higher potential for the extraction of value-added minerals at a better percentage by reducing or preventing hydraulic traction of undesirable portions [75].

\subsubsection{Oil Agglomeration}

The working mechanism of oil aggregation $(\mathrm{O} / \mathrm{A})$ is similar to froth flotation. In the oil aggregation technique, oil is added to the slurry containing CFA and water. As a result, oil wets the oleophilic/hydrophobic UC particles either partly or completely [15]. Due to the wetting of UC particles, it is moistened while the residual CFA particles remain as a slurry. In order to properly mix oil and UC particles, the tanks are fitted with stirrers or agitators and the UC or carbon particles are coated with oil present in the slurry. Further, several oil-coated UC particles adhere together by colliding with each other, which is also favored by stirring or agitation. Due to collision, there is a formation of large aggregates of carbon or UC particles, which rise above the slurry as UCs have a lower density than the other minerals particles in the slurry which are left behind in the slurry. The UC particles which rise above are easily separated from the slurry [38,76]. From extensive literature, it was revealed that, by applying the O/A technique, it is possible to achieve a purity of $66-71 \%$ of carbon and to maintain a recovery at about $55-75 \%$ at the same time $[77,78]$.

\subsubsection{Density Separation (Sink-Float Technique)}

These methods of skin-float are explored but have not yet been applied on a commercial basis like the methods reported in the previous section. The density separation technique indulges three physical parameters, i.e., bulk density (BD), envelope density, and skeletal density [79]. The bulk density can be described as the volume of pores and intraparticle space. The second factor, i.e., envelope density (ED), considers the volume of the skeleton and pores, and the third factor, i.e., skeletal density (SD), only refers to the volume of the skeleton [80]. From various literature investigations, it has been found that the abovementioned three physical factors increase for UC in the following order: BD, ED, and SD.

CFAs have two fractions, i.e., carbon fractions and mineral fractions; therefore, in the slurry, heavier mineral fractions settle down and form the "sink" fraction while the less dense carbon fractions float at the top and become part of the "float" fraction [70]. These two fractions sometimes are separated by using a certain liquid medium, e.g., tungstate [79]. In this process, a tube or tank having a slurry of CFA and liquid medium is fitted with a gas flow inlet. This gas flow is pulled upward in the tube due to the heavier density mineral fractions settling down in the tube or tank while the less dense UC particles float at the top of the tube or tank. The most commonly used gas in this method is $\mathrm{H}_{2}$ due to its inert nature; hence, the particles remain in their unreacted form [81]. By applying the sink float technique (SFT), not only a UC of high purity can be obtained, e.g., 75\% [81], but also the contamination and alteration of the property of unburned carbon can be avoided [81] as chemical reagents are not used. 


\subsection{Dry Separation Method}

This method of dry separation for carbon recovery or separation methods does not need any liquid media, and moreover, the particles stay undamaged in the dry phase. Therefore, such methods have advantages over the wet-based processes for the extraction of carbon particles from CFA or from other carbon sources [66]. There are different methods for the dry separation of carbon from CFA, but some of the most important methods are separation by size classification [82], incipient fluidization, electrostatic separation, and tribo-electrostatic separation (TES) $[83,84]$. All these methods of dry separation are discussed below.

\subsubsection{Separation by Size Classification}

Several high-unburned carbon CFAs encompass an uneven quantity of coarser (i.e. $>150 \mu \mathrm{m}$ ) C particles. These coarse-sized portions habitually represent less than $10 \%$ of the total mass and often consists of as much as $50 \%$ of the present carbon. The separation efficiency by this particular method is reliant on the particle-size distribution of the UC in the CFA. As such, classification by size could be an active means of selective $C$ recovery, especially when a bulk quantity of coarse $C$ exists. The separation efficiency of $\mathrm{UC}$ is less when there is an even distribution of UCs within certain particle-size fractions in the CFA [82].

Size-based classification techniques do not involve any liquid medium for the separation of UC and CFA particles [15]. Therefore, here, the separation takes place based on their size and density, generally by screening [66]. One most common method is separation of particles based on dry screening, which will separate the fine UC particles from coarse or irregular UC particles. However, this technique is not very efficient since other mineral particles will also be present in the sample. Therefore, this technique is not feasible for the separation of fine particles on a large scale.

Another method is cyclone classifier, which is a cylinder with an airstream at the bottom $[61,66]$. Due to the air stream, there will be centrifugal forces on the larger or irregular particles, which will leave the cylinder from the bottom, while the finer UC particles will join the air stream in the center, will be vortexed, and will exit from the cyclone classifier from the inner core.

There are also commercial air classifiers [30], of which most of the working mechanism is the same but may have different feed arrangements. Since the density of UC particles $\left(1.8 \mathrm{~g} / \mathrm{cm}^{3}\right)$ is less than the mineral particles $\left(2.5 \mathrm{~g} / \mathrm{cm}^{3}\right)$, this principle is utilized by the commercial air classifiers for separation $[85,86]$. This technique is suitable for the removal of finer carbon fractions due to lower efficiency. Abrasive UC particles of low density will be rejected in such separators, but as the density of finer UC particles are less than the mineral particles, the finer carbons will be collected along with finer ash particles in the vortex exit stream [87].

\subsubsection{Electrostatic Separation (ES)}

The ES technique is a quite different technique from all the previously discussed technique since it neither separates based on size nor utilizes a liquid medium [85]. This techniques utilizes the charge differences of the carbon particles and other mineral particles from the CFA [88]. These particles are charged due to inner particle contact where there is a transfer of charges between the particles due to electron affinity differences. The carbon or UC particles have lower electron affinity, so the electrons are loosened and in turn become positively charged. On the other hand, the mineral phases takes the electrons from carbon and become negatively charged, and hence, this differential charge acts as the basis for ES. Several investigators have reported the extraction of UC or carbon particles using this method and have been commercially approved [78,89-91]. 


\subsubsection{Incipient Fluidization}

Incipient fluidization is a carbon-separation method based on a dry technique which makes use of a glass tube that has a lower quantity of CFA inside [38,92]. Short jets of gases are introduced from the bottom and push the ash CFA sample upwards, where the CFA is successively permitted to settle down. The heavier CFA particles settles at the bottom, while the finer light particles (UC) of CFA floats inside the tube. One major benefit of this technique is that there is no possibility of leakage or contamination; hence, high-purity carbon $(75 \% \mathrm{C})$ can be easily obtained [93].

\subsubsection{Tribo-Electrostatic Separation (TES)}

In the industry, tribo-electrostatic separation is used globally to recover and separate carbon materials from CFA and other sources [94]. The tribo-electrostatic separator is mainly manufactured with two vertical electrodes and an ejector. The CFA particles are electro statistically charged, and when they are between the electrodes, then the UC particles are separately collected as per their load (as char particles of CFA are attracted to the negative electrode) [95]. The presence of moisture in the CFA particles can lead to undesirable behavior of the equipment.

Table 2. Various techniques applied for the recovery of carbonaceous particles from CFA.

\begin{tabular}{ccc}
\hline Method & References & Efficiency/Findings \\
\hline Froth flotation & 1. Wet Separation Method \\
\hline Oil agglomeration & {$[64,78,96]$} & $\begin{array}{c}\text { Simple method; no liquid media used; } \\
\text { and less space for machinery, less energy } \\
\text { required, and high recovering capacity }\end{array}$ \\
\hline Density separation & {$[79,97]$} & $\begin{array}{c}\text { Provides highly pure unburned carbon } \\
\text { with higher recoveries }\end{array}$ \\
\hline Separation by size classification & 2. Dry Separation Method & $\begin{array}{c}\text { Provides unburnt high purity carbon; no } \\
\text { or alterations in the properties of carbon }\end{array}$ \\
\hline Electrostatic separation & {$[87]$} & $\begin{array}{c}\text { Separates the UC particles on the basis of } \\
\text { size and density }\end{array}$ \\
\hline Incipient fluidization & {$[78,90,91]$} & $\begin{array}{c}\text { Separates the UC particles on the basis of } \\
\text { electron affinity }\end{array}$ \\
\hline Tribo-electrostatic separation & {$[98]$} & $\begin{array}{c}\text { Provides highly pure carbon; No danger } \\
\text { of leakage or contamination. }\end{array}$ \\
\hline [95] & $\begin{array}{c}\text { Electrostatic-based separation of UC } \\
\text { particles between two electrodes }\end{array}$ \\
\hline
\end{tabular}

\section{Types of Carbon Nanomaterial Present in CFA}

\subsection{Fullerene}

Fullerene was the first molecule to be discovered. The core of a "bucky onion" [99,100] was independently reported by 60 different researchers in the early 1980s. Earlier, only graphite and diamond were known, but after the discovery of fullerene, there was significant contribution in the carbon allotropy field. The unique and remarkable properties of fullerene attracted several investigators to develop potential technological applications. $\mathrm{C}_{60}$ carbon clusters are mainly electron acceptors, and thus, fullerenes is widely used for developing renewable energy sources.

\section{Fullerene and Fullerene-Like Materials in CFA}

Fullerenes and CNTs are both carbon-based nanomaterials with hollow spherical shapes which attained scientific devotion due to its economic value [101]. Dosodia et al., 
2009, provided proof of the presence of fullerene in geological minerals, specifically in coal-derived CFAs [102]. Nanoparticles including fullerenes are generally produced during the combustion of coal and in coal-handling process as a byproduct covered with other hazardous elements [103]. Further, Tiwari et al., 2016, concluded that, besides the above by-products, there is formation of fullerene aggregates $\left(\mathrm{C}_{60}\right)$ in terms of mass of $\mathrm{C}_{60}$ per mass of particulate matter while handling coal combustion activities $[104,105]$. The HRTEM investigation revealed that there is an abundance of fullerene content on the agglomerates of nanocarbon surfaces. A fullerene molecule extracted from CFA generally varies in size [106]. The detailed morphological analysis of fullerene revealed that some of the nanocarbons have fullerene-like structures, suggesting that the growth mechanism of nanocarbon is somewhat similar to that of fullerene. Further, some of the investigators observed fullerene-like soot in the nanocarbon sitting on the surface of aluminosilicate spheres of CFA, justifying that primary fullerene particles are arranged in a chain-like assembly [107]. Such fullerene-like structures shows multi-shelled structures, which are interlinked by evidence of the appearance of strongly bent graphene sheets or ribbons and double shells. When the CFA is used as a supporting material for the synthesis of nanocarbon, fullerene synthesis on the CFA nanocarbons tends to depend on the temperature and affects the concentrations of water vapor and $\mathrm{CO}_{2}$ as well as their size formed [7].

\subsection{Nanocarbon and Nanocoating}

There exists the presence of ultrafine particulate matters (PM) carbon in CFA, which is either present as nanoscale sooty or graphitic fullerene-like carbons. Dozier et al., 2008, reported the presence of several types of nanocarbon materials in the CFA, especially the ultrafine PM carbon material, from a high volatile bituminous CFA [108]. Such nanocarbons are collected in the electrostatic precipitators (ESP units) of thermal power plants (TPPs), where they either settle or are intermixed with bigger spheres of aluminosilicate glassy CFA [109]. Subsequently, they produce an extremely thin covering on the external surface of inorganic CFA particles, which appears as a nanocoating which covers glassy CFA spherical particles in a capsule-type system [7]. The nanocarbons are commonly found around the main stream of aluminosilicate glass CFA spheres as an ultrathin layers. Such shells or nano-scaled coatings of carbon are formed from aggregated soot particles and are highly porous [85]. The analysis of a carbon-loaded CFA having higher concentrations of mercury $(1-3 \mu \mathrm{g} / \mathrm{g})$, Arsenic $\left(10^{2}-10^{3} \mu \mathrm{g} / \mathrm{g}\right)$, and Selenium $\left(10^{2} \mu \mathrm{g} / \mathrm{g}\right)$ carried out using sophisticated instruments like scanning transmission electron microscopy (STEM), HRTEM, and electron energy loss spectroscopy (EELS) showed that the nanocarbons (either with soot-like or fullerene-like structures) comprise finely distributed nano-sized metallic inclusions [1]. The elements and their amount in metallic were observed in the following order: $\mathrm{Hg}<\mathrm{Co}<\mathrm{Ni}<\mathrm{As}<\mathrm{Pb}<\mathrm{Ti}<\mathrm{Ca}<\mathrm{Hg}$ along with $\mathrm{Se}$ in fluctuating concentrations. The study revealed that the major part of aluminosilicate glass spheres have a carbon nanocoating. It is quite obvious that the thickness of the carbon nanocoating shows a discrepancy amid various CFA aluminosilicate spherical particles captured in ESP units that can be uneven on individual sphere surface; the deposition of such nanocarbons seem to impede the smoothness and fluidity of the CFA particles. In their findings, the EELS spectrum of particular metallic inclusions in the agglomerates of nanocarbon showed that a major part of the nanoparticle-sized metals are Fe-rich. Moreover, $\mathrm{Pb}, \mathrm{Co}, \mathrm{As}$, Se, and bits of titanium and barium are frequently linked with Fe-rich particles inside the depositions of nanocarbon. Further, the elemental analysis revealed the association of mercury with the nanocarbon.

\subsection{Carbon Nanotubes and Their Properties in CFA}

Carbon nanotubes (CNTs) are a member of the fullerene structural family, and since their discovery, they have been of great interest among scientists $[19,110]$. There is a wide market potential of CNTs in numerous area for instance telecommunication, catalysis, electronics, computer sciences, nano-mechanics, microscopes, and biological and chemical 
sciences [102,111]. CNTs are the most interesting carbon nanomaterials [31] and have been extensively studied and evaluated for their diverse applications in a range of scientific and technical fields. A CNT is a typical 1-dimensional structural allotrope of $C$ which has a tubular structure made up of hexagonally arranged carbon atoms. These nanotubes may vary in length up to a few millimeters and diameter in the nanometer scale. From, the literatures it is proven that single-walled carbon nanotubes (SWCNTs) and multi-walled carbon nanotubes (MWCNTs) are the two basic forms of CNTs. Most of the SWCNTs have diameters in the nano range, with a tube length of many folds longer. The SWCNT structure is the same as that of a "single-atom-thick" layer of grapheme sheet folded into a cylinder of seamless type [112], while the structure of MWCNTs resembles multi-rolled graphite $[113,114]$. The distance among the various layers in MWCNTs is approximately $3.4 \AA$, which is almost adjacent to the distance amongst graphene layers in graphite [115]. In MWCNTs, each individual shell can be labelled as a single walled nanotube, which can be either semiconducting or metallic [116]. The MWCNT behaves like a zero-gap metal due to statistical probability and restrictions on the relative diameters of the individual tubes.

The formation of CNTs in the CFA from the Gondwana region of India, reported by a group of investigators where the diameters of the formed CNTs vary from 18 to $24 \mathrm{~nm}$. They also reported the presence of branch carbon nanotubes (BCNTs) in those CFA whose diameter was observed to vary from 35 to $92 \mathrm{~nm}[117,118]$. They suggested that value-added products derived from such nanocarbons can be prepared using low-grade coals. The amorphous and crystalline CNTs associated with several other elements and nanominerals were also reported by several investigators like Dias et al., 2014; Martinello et al., 2014; and so on [119-121]. The analysis report of HRTEM showed some weak metallic and or support interactions with CNTs tip growth. The results also suggested that, at this analysis scale, it is not possible to find out whether the metals are bound to the side of the structure or within the fullerene balls. In environmental science, the encasement of potentially hazardous elements (e.g., $\mathrm{Hg}, \mathrm{Cd}, \mathrm{Ni}, \mathrm{Cr}$, As, Co etc.) inside the MWCNTs is of huge significance. A significant quantity of nanotube terminal ends are detectable in the CFA mainly after 4th step [122], comprising both the terminals at hazardous metallic particles and metallo-fullerenes, contributing a chance to inspect dimensionally confined systems. In this study, the carbon-encased hazardous-element nanoparticles deliver chemical steadiness and protects from agglomeration in elemental nanoparticles while the core metal particles may be responsible for the specific functions that are unobtainable in bulk form.

The purification of CNTs can be further done by using various processes such as filtration, electrochemical oxidation, ultra-sonication, gas phase oxidation, microwave purification, magnetic separation, liquid phase oxidation, and centrifugation [123]. The removal of impurities of CNTs enhances their wider acceptance in industries for numerous applications, for instance, in the fields of textile [101], body armors, concrete, polyethylene, bridges, fly wheels, and fire protection due to their structural properties [124,125]. Further, CNTs are widely used in solar cells, light bulb filaments [126], electromagnetic antennae [127], and bucky paper [128] due to their ability to conduct electricity [126,129]. Due to its inert chemical property, it is widely used in sensors, filters for air and water pollution, and chemical nanowires [130].

\subsection{Carbon Nanoballs}

There is formation of carbon nanoballs in the CFA where the observed nanoballs had sizes varying from 5 to $10 \mathrm{~nm}$ and small areas in the size ranges of $40-100 \mathrm{~nm}^{2}$, $160-220 \mathrm{~nm}^{2}$, and $550-650 \mathrm{~nm}^{2}$. These carbon nanoballs were found to have a layered structure like multi-walled CNTs, and these nanoballs are not common with this type of raw or untreated coal [117]. HRTEM data revealed that most of the carbon species were in the size range of 10-200 nm carbon nanoballs, similar to black carbon (or soot) with concentrically arranged graphite sheets [131].

The fractal organized masses differ in size and unveil a micro-texture that is comprise of co-centrically arranged graphitic sheets. This is a prime constituent of smoke from 
the combustion of carbon-rich organic fuels in conditions with oxygen deficiency and an arrangement of amorphous carbon that provides a CFA-like appearance of a dark and damp powder [132]. In pollution control devices, when the flue gas and fly ash cool down, numerous hazardous elements and carbon-particle agglomerates form through a mechanism of vaporization-condensation. The existence of these particles in CFA samples with residues of carbon identified by crucial analysis and HRTEM or EDS advises incomplete combustion of coal.

Figures 2 and 3 depict the TEM and HRTEM images, respectively, of carbon nanoballs separated from the CFA from diverse parts of the world. The carbon nanoballs are spherical in shape in Figure 2A, while in Figure 2B, it is spherical but irregular also. The sizes are well below $100 \mathrm{~nm}$ in both images. Figure 3A,B shows HRTEM images of nanocarbons at the 10and 5-nm scales. The HRTEM clearly shows spherical to near spherical shapes and lattice fringes of nanocarbon particles. Thus, the coal and coal CFA might be a substitute method for nanocarbon production at less cost compared to the available harsh methods [117].
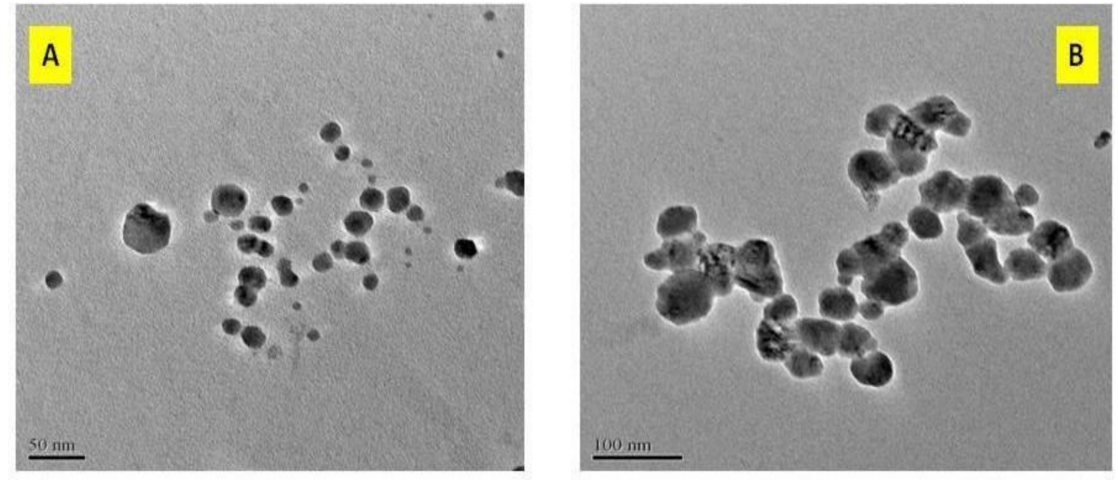

Figure 2. (A,B) TEM images of CFA carbon nanoballs adapted from Das et al., 2016 [117].
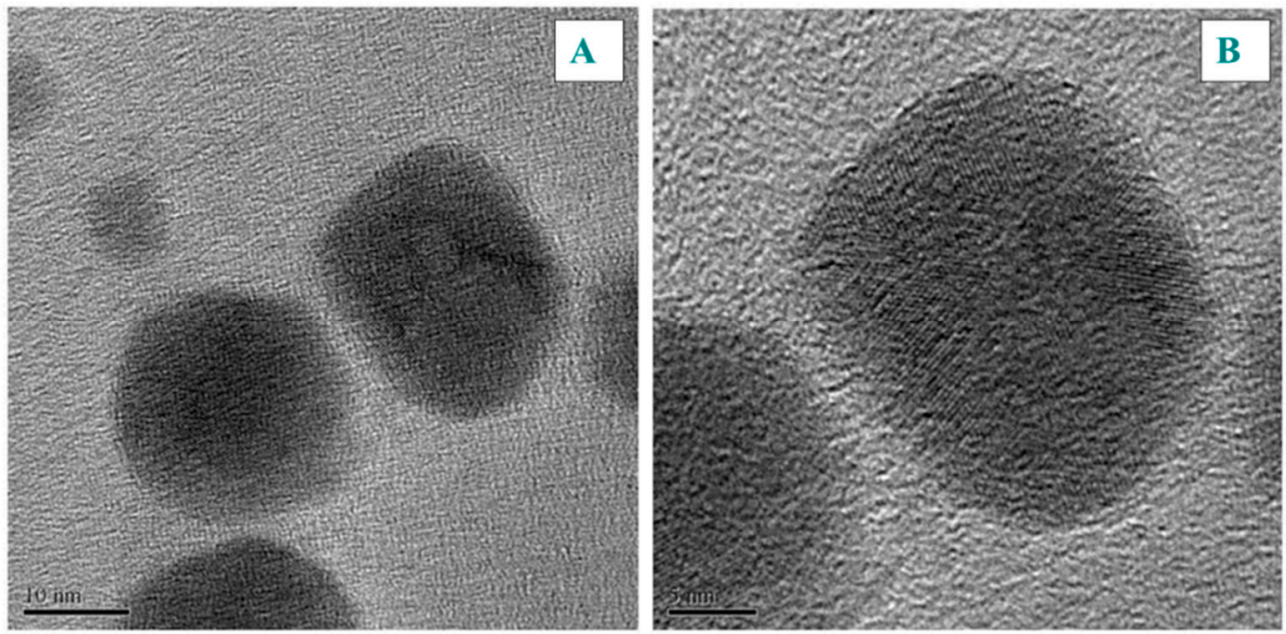

Figure 3. (A,B) High-resolution transmission scanning electron microscopy (HRTEM) images showing lattice fringes of the carbon nanoballs at 5-10 nm adapted from Das et al., 2016 [117].

\subsection{Carbon Onions}

Several investigators have reported and characterized the presence of concentric, multi-shelled nano-scaled carbon polyhedra [133], indicative of high thermal behaviors of soot that are catalyzed by metals that alter the agglomerate of soot that is amorphous to normal fullerenes. During this process, the fragments of the precursors are curled around the catalytic metal, while fragments of flat sheet also form nano spherule aggregates. Such particles have considerable importance in environmental science as they can encapsulate elements like $\mathrm{Cd}, \mathrm{Hg}, \mathrm{Co}, \mathrm{Ni}, \mathrm{Cr}$, and As inside the MWNTs that are potentially hazardous. 


\subsection{Extraction of Soot and Chars from CFA}

CFAs are a great source of soot and chars, which are generally unburned carbon in CFA after combustion.

\subsubsection{Chars}

The carbon nanomaterials of CFA exist either in small-sized char form or in the form of smaller particle aggregates that form large-sized particle. Chars are basically porous, high carbon-content particles which, throughout combustion, stay in a solid or liquid phase. The carbon residues or char may be coal particles which remain unreacted due to the coal that transforms chemically in the absence of oxygen [55].

A typical SEM micrograph of a porous carbonaceous CFA char particle is shown in Figure 4, obtained from the bottom CFA fraction adapted from Veranth et al. [134]. The extracted porous char particles are irregular in shape and carbon rich, as shown by the SEM.

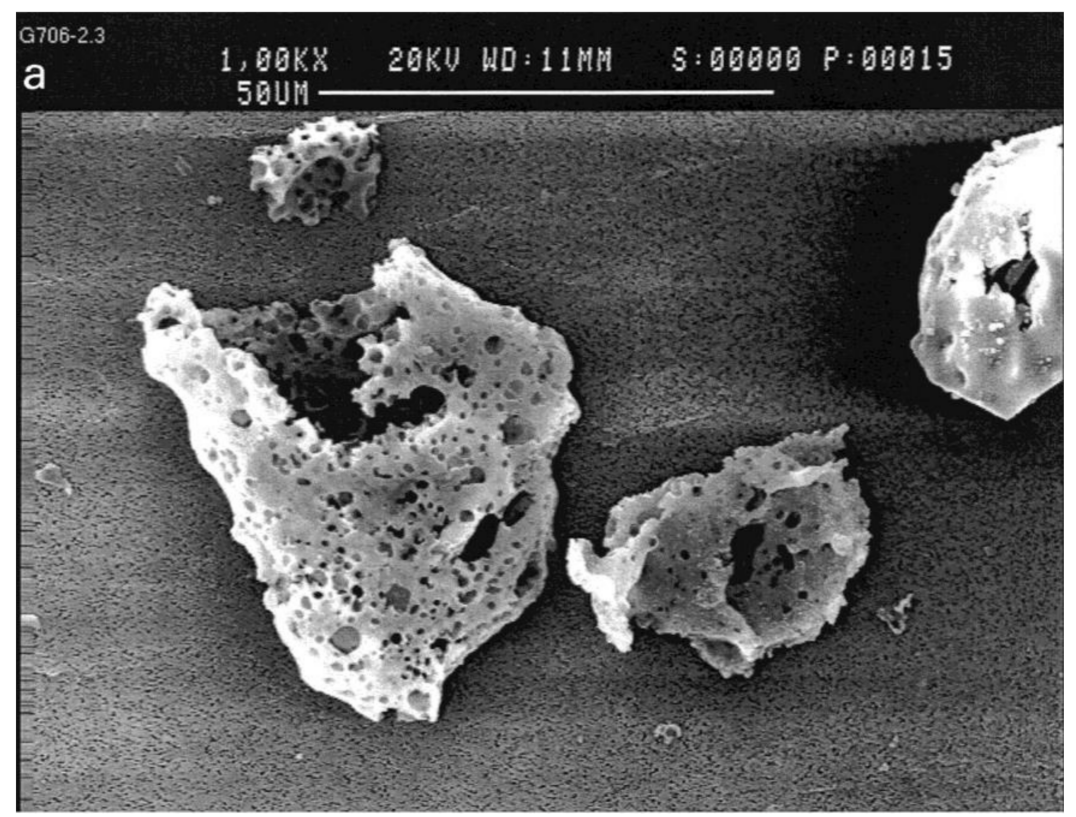

Figure 4. SEM image of porous char particles from the bottom CFA fraction adapted from Veranth et al., 2000 [135].

\subsubsection{Soot}

Soot is a mass of ultrafine carbon-rich particles generated from gas-phase precursors. The soot is generally identified by electron microscope and present in the form of masses that are about $10-50 \mathrm{~nm}$ diameter in size. Primary soot particles which range in the size of $10-100 \mathrm{~nm}$ diameter can form aggregates by coagulation that are macroscopic. At elevated temperatures, when there is insufficient time for complete oxidation of soot, the formation of soot aggregates are produced by incomplete combustion between the end of the fuel-rich zone and the exit of the furnace. During burning of powdered coal, they are converted into pore-bearing, irregular char by the process of heterogeneous partial oxidation and devolatilization [134]. In the soot, carbons include nanotubes encapsulating $\mathrm{Hg}$, metalbearing multi-walled nanotubes, a complex particles of carbon, and structures similar to an onion with quasi-spherical and few polyhedral morphology-like hollow centers [136]. In soot, nitrogen enrichment is allied with the fractionation of ammonia in salammoniac formation. $\mathrm{Zn}, \mathrm{Pb}$, and Se are found in comparatively high amounts in the soot and fly ash CNTs. Human-made amorphous or crystalline mixed complex nanominerals, and fullerenes have been discovered with numerous geological resources in trace concentration $[108,137]$. Until now, several researchers globally reported the occurrence of fullerenes which are of great interest since their discovery in natural systems. Their cage structure 
was described by several investigators, recalling some possibly hazardous elements [138]. Several researchers also reported the presence of both types of CNTs in the CFA. From the above literature, it was revealed that CFAs have soot consisting of numerous carbonaceous nanoparticles like fullerene, CNTs, carbon onions [139], etc., which are briefed in Table 3, whereas chars in CFA were reported to have several types of hydrocarbons as well.

Table 3. Different carbon nanomaterials extracted from CFA.

\begin{tabular}{ccc}
\hline Type of carbon NMs & References & Efficiency/Description of CNMs \\
\hline Fullerene $\left(\mathbf{C}_{60}\right)$ & {$[100,102,104,105]$} & Hollow, spherical \\
\hline Nanocarbon and nanocoating & {$[108,109,140]$} & $\begin{array}{c}\text { Nanoscale sooty or graphitic } \\
\text { fullerene-like carbons; } \\
\text { porous nanocoating }\end{array}$ \\
\hline Carbon nanotubes & {$[31,102,110,120]$} & $\begin{array}{c}\text { SWCNTs and MWCNTs; diameter of } \\
\text { 8-20 nm; amorphous and } \\
\text { crystalline nature }\end{array}$ \\
\hline Carbon nanoballs & {$[132]$} & 5-10 nm \\
\hline Carbon onions & {$[133]$} & Nanopolyhedra, onion-like, concentric \\
\hline Chars & {$[24,141]$} & porous, carbon-rich particles \\
\hline Soots & {$[108,136]$} & $\begin{array}{c}\text { Ultrafine primary particles; aggregates } \\
\text { of 10-50 nm diameter }\end{array}$ \\
\hline
\end{tabular}

\section{Properties of Carbon Nanomaterials from CFA}

The chief carbon constituents in CFA are mixtures of soot and chars termed unburned carbon, the composition of which varies from $1 \%$ to $12 \%$ and is easily observed by electron microscope [30]. On close examination by microscopy, one can differentiate and identify the CNTS, fullerenes, nanoballs, and carbon onions which are always associated with alkali and heavy metals in trace amounts in the CFA. Unburnt carbons' surface area differs depending on the parent coal and combustion time. Primarily as microporous structures, CFA carbon rarely exceeds $10 \mathrm{~m}^{2} / \mathrm{g}$, with the majority of its surface area associated with mesopores and macropores. The CFA mainly has two components namely; UC and mineral matter, whose surface areas are $45-400 \mathrm{~m}^{2} / \mathrm{g}$ and $\left(0.7-0.8 \mathrm{~m}^{2} / \mathrm{g}\right)$, respectively. Therefore, it is quite obvious that the UCs have much higher surface areas than that of mineral matters of CFA, so UCs can be used as an efficient adsorbent for numerous applications [142].

\section{PAHs in CFA and Bottom Ash}

The behavior of PAHs is mainly determined by their physical and chemical properties. In atmospheric conditions, PAHs are semi-volatile, usually occur in the vapor phase, and are attached to the particles depending on the individual PAH's vapor pressure [101,102,142]. The PAHs having low molecular weight, with 2 or 3 fused rings, go through volatilization with their prime presence in the vapor phase, whereas PAHs having high molecular weight with more than 3 fused rings are mainly connected with particles and are adsorbed on particulate matter [103]. The combustor halting time along with the surface area of the fly ash particles are the main motives for enhancement of PAHs in coal fly ash.

\subsection{Formation of PAHs in Coal}

During the processes of combustion, organic fragments are released which initiate cyclisation or radical condensation reactions. These reactions lead to the formation of PAHs, which are generated as gases or fine particulate matter [143-145]. Combustion brings about chemical and physical changes in coal structure which result in the release of organic fractions [146]. The process is followed by cyclization or radical condensation reactions which lead to formation of polycyclic compounds in the form of fine particulate matter or gases [147]. During coal burning, the two possible sources of PAHs formation 
are incomplete combustion and chemical changes. The former results in the emission of fragments primarily with the aromatic structure of the coal [13]. Here, the presence of the phenanthrene type of aromatic compound in feed coal supports this view while considering the majority of such compounds. The formation of a higher amount of 4-, 5-, and 6-ring PAHs in CFA takes place through the polymerization process caused by bond cleavage; free radical condensation occurred as a result of chemical fluctuations of unstable hydrocarbons [148].

\subsection{Extraction Method of PAHs from CFA}

PAHs can be extracted from CFA using ultrasonic extraction, organic solvent extraction, supercritical fluid extraction, soxhlet extraction method, and accelerated solvent extraction $[149,150]$. Furthermore, the solvent extraction method and other cleaning and concentration stages are very time-consuming and labor-intensive [151]. Usually, the soxhlet extraction process includes the use of various of environmentally hazardous solvents and has a performance time of 6 to 24 hours [152].

One such method of PAH extraction from CFA is given here. For analysis of PAH, samples were isolated by utilizing a 1:1 acetone-hexane mixture in an extraction system of microwave (Milestone, Italy) according to the USEPA method 3546 (USEPA Method 1995) [153]. About $5 \mathrm{~g}$ of a sample was placed in a Teflon vessel, and $30 \mathrm{ml}$ of the acetonehexane $(1: 1 \mathrm{v} / \mathrm{v})$ mixture was added to it. The vessels were then heated in a microwave extraction system at $120^{\circ} \mathrm{C}$ for $30 \mathrm{~min}$ (Milestone, Italy). After extraction, the samples were allowed to cool down, filtered, and cleaned using silica gel as per the USEPA Method $363^{\circ} \mathrm{C}$. The extracts were concentrated to $1.0 \mathrm{ml}$ with a gentle flow of molecular nitrogen [154].

\subsection{Methods for Analysis of PAHs}

Gas chromatography plays a vital role in the analysis of PAHs extracted from waste material like CFA. Moreover, gas chromatography (GC) alone is sufficient alone but is sometimes coupled with mass spectrometry (MS) [155]. The GCMS technique is relatively sensitive and highly selective for the analysis of PAHs. If the PAHs are non-volatile, then the molecular information is often hampered by the GC technique. In this state, the information can be collected only for aromatic systems with 5 or 6 condensed rings with approximately 300 molecular weight. Mastral [156] along with other investigators reported that there are 16 types of PAHs in CFA. Further, they revealed that, out of these 16 types of PAHs, only four of them, i.e., Chy (3 ring), Fla (4 ring), DahA (5 ring), and BghiP (6 ring), were present below the detection value, while the concentrations of the remaining 16 compounds in the coal were much greater $(1.2-956 \mu \mathrm{g} / \mathrm{kg})$ than both CFA $(0.1-20.9 \mu \mathrm{g} / \mathrm{kg})$ and bottom ash (BA) $(0.2-3.2 \mu \mathrm{g} / \mathrm{kg})$, while in the lower grades of coal, about $13-14 \mathrm{mg} / \mathrm{kg}$ of PAHs was found. Finally, it was concluded that both coal and CFA had relatively large amounts of compounds having 4-6 rings compared to compounds having 2-3 rings. In bottom ash, low molecular compounds were more common than the high molecular weight compounds [155].

\subsection{Properties of PAHs Extracted from CFA}

We have already seen that PAHs are organic compounds, which are mainly hydrophobic and relatively insoluble in water [157]. Such PAHs compounds have much higher affinity for organic matter. This property favors them when soil or sediment is present; then, PAHs tend to remain as solid constituents and dissolve in water very slowly. PAHs are generally a group of universally persistent organic pollutants (POPs) which have both mutagenic and carcinogenic properties [158]. These particulate PAHs are generally distributed across the spectrum of particle sizes according to their molecular weight. More specifically, low molecular weight PAHs are mainly present with large-sized particles [26]. In CFA, PAHs are mainly present with carbon particles, which are present in much lesser mass fractions of the total composition [144]. 


\section{Applications of CNMs, Unburned Carbon, and PAHs of CFA}

The carbon fractions, unburned particles, obtained from CFA can be utilized either directly or after purification for various purposes. For instance, the recovered carbon nanomaterial can be utilized as an economical, potential adsorbent material replacing activated carbon for flue gas treatment and wastewater treatment. From the various investigations, it was found that the more the carbon content in CFA, the higher will be its adsorption efficiency for flue gas and waste water treatment [159]. In wastewater treatment, it is used for the nano-remediation of dyes, heavy metals, microbes, antibiotics, and other pollutants $[160,161]$. It is widely used as an adsorbent for mercury, which depends on the percentage of unburned carbon in the CFA and the nature of unburned carbon [147]. In addition to the abovementioned applications, carbon (both burned and unburned) could be utilized as a precious and economical source of activated carbon [162], which needs only some surface modification and activation [79]. There are several reports where it has been used as a catalytic agent in low-temperature nitrogen oxide reduction with $\mathrm{NH}_{3}[163,164]$. Moreover, the recovered carbon nanomaterial can be used as value-added minerals by using them as an economical carbon source for feedback to the furnace boiler in TPPs $[1,37]$.

The recovered unburnt carbons are widely used for manufacturing a large number of premium carbon products, i.e., natural or synthesized nanostructured carbon materials and could fulfill the raw material demand of several carbon-based industries [165]. Until now, such recovered carbon particles from CFA were successfully used as an activated carbon, graphite substitutes [166], absorbents as well as adsorbents [167], lithium-ion batteries, supercapacitors [168,169], environmental remediation and protection [170], and solar cells. Moreover, there are a plenty of areas where carbon particles can be applied, but the major areas are shown above in Figure 5.

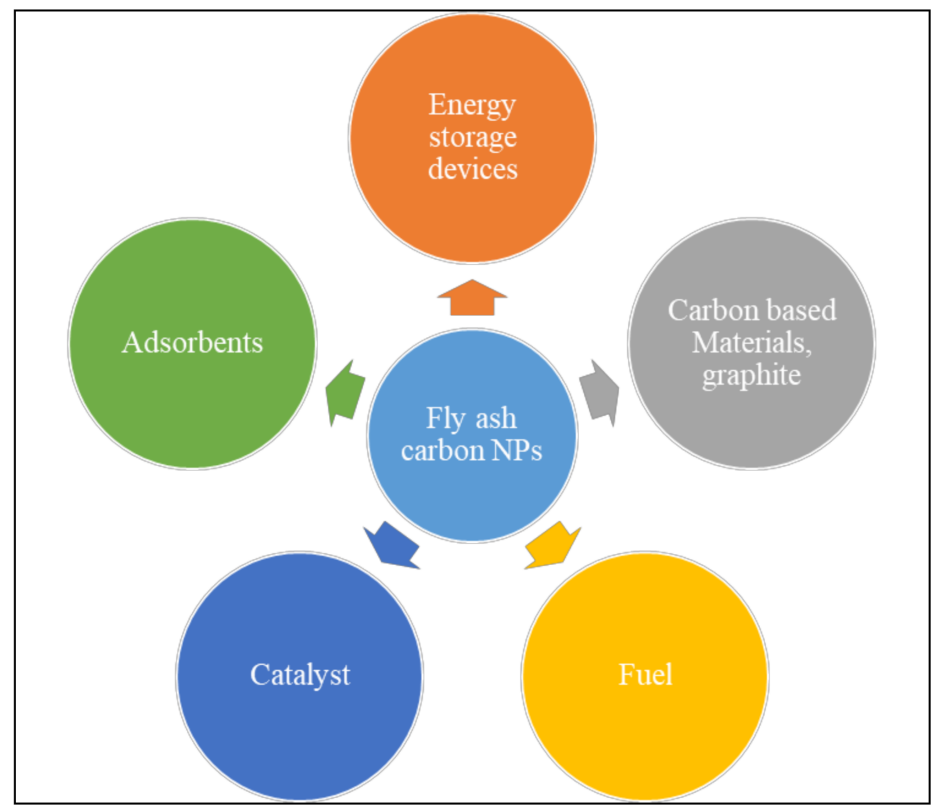

Figure 5. Applications of CFA carbon nanomaterials.

\section{Conclusions}

Among all the nanomaterials, nanostructured carbon materials has gained huge importance due to their wide allotropes, economic value, and availability. The extraction or synthesis of carbon nanomaterials from waste-like high-carbon CFA, agricultural waste, and other industrial wastes provides a greener approach as it is recycled and reduces pollution. Carbon nanomaterials formed from CFAs provide an alternative source of carbon at a very low cost. CFA has fullerenes, CNTs, CNFs, carbon onions, and other composite materials which are mainly associated with traces of alkali metals and heavy 
metals which are captured during volatilization of the minerals in thermal power plants. After purification, such natural or synthesized nanostructured carbon materials can be used in place of commercially synthesized nanocarbons for energy storage devices. It also suggests an economical and eco-friendly solution for land fill-based disposal of CFA, which in turn can solve numerous serious environmental problems. The extraction or removal of toxic PAHs and PCHs from CFA increases the acceptability of CFAs. Thus, the nanostructured carbon materials hold promising applications in the future due to their high surface-to-volume ratio, high surface energy, and better adsorption capacity.

Author Contributions: Conceptualization, V.K.Y., A.K.S., J.A. and N.C.; methodology, V.K.Y., N.T., and A.K.S.; software, K.K.Y., A.A.H., and N.C.; validation J.A., K.K.Y., V.K.Y., and A.A.H.; formal analysis, F.A.A.A., and M.M.S.C.-P.; investigation, F.A.A.A.; N.T., K.K.Y., M.A., and V.K.Y., resources, M.M.S.C.-P., V.K.Y.,; data curation, M.M.S.C.-P., A.A.H., M.A., and A.K.S.; writing-original draft preparation, V.K.Y.; writing - review and editing, V.K.Y., N.T., N.C, K.K.Y. and J.A.; visualization, N.T., V.K.Y., N.C., M.A., and J.A.; supervision, M.M.S.C.-P., F.A.A.A., and K.K.Y.; project administration, A.A.H., M.A., F.A.A.A., and V.K.Y.; funding acquisition, M.M.S.C.-P., F.A.A.A., A.A.H., A.K.S., J.A., and M.A. All authors have read and agreed to the published version of the manuscript.

Funding: The authors extend their appreciation to the Deputyship for Research and Innovation, "Ministry of Education" in Saudi Arabia for funding this research work through the Project no. (IFKSURP-1439-085).

Conflicts of Interest: The authors declare that there is no conflict of interest.

$\begin{array}{ll}\text { Abbreviations } \\ \text { BCNTs } & \text { Branched carbon nanotubes } \\ \text { BD } & \text { Bulk density } \\ \text { BPAA } & \text { Bubble-particle attachment angle } \\ \text { CEA } & \text { Central electrical agency } \\ \text { CF } & \text { Calorific value } \\ \text { CFA } & \text { Coal fly ash } \\ \text { CNFs } & \text { Carbon nano-fullerenes } \\ \text { CNMs } & \text { Carbon nanomaterials } \\ \text { CNTS } & \text { Carbon nanotubes } \\ \text { ED } & \text { Envelope density } \\ \text { EDS } & \text { Electron diffraction spectroscopy } \\ \text { EELS } & \text { Electron energy loss spectroscopy } \\ \text { ESCA } & \text { Electron scattering chemical analysis } \\ \text { ESP } & \text { Electrostatic precipitator } \\ \text { FA } & \text { Fly ash } \\ \text { FF } & \text { Froth flotation } \\ \text { GC } & \text { Gas chromatography } \\ \text { GCMS } & \text { Gas chromatography mass spectroscopy } \\ \text { HCFA } & \text { High carbon fly ash } \\ \text { HRTEM } & \text { High-resolution transmission scanning electron microscopy } \\ \text { IEA } & \text { International energy authority } \\ \text { LOI } & \text { Loss on ignition } \\ \text { MTs } & \text { Million tons } \\ \text { MWCNTs } & \text { Multi-walled carbon nanotubes } \\ \text { NPs } & \text { Nanoparticles } \\ \text { PAHs } & \text { Polyaromatic hydrocarbons } \\ \text { PCHs } & \text { Polycyclic hydrocarbons } \\ \text { PM } & \text { Particulate matters } \\ \text { POPs } & \text { Persistent organic pollutants } \\ \text { SD } & \text { Skeleton density } \\ \text { SEM } & \text { Scanning electron microscope } \\ \text { SFT } & \text { Sink-float technique } \\ \text { STEM } & \text { Scanning tunneling electron microscope } \\ & \end{array}$




$\begin{array}{ll}\text { SVR } & \text { Surface area-to-volume ratio } \\ \text { SWCNTs } & \text { Single walled carbon nanotubes } \\ \text { TEM } & \text { Transmission electron microscopy } \\ \text { TES } & \text { Tribo-electrostatic separator } \\ \text { TGA } & \text { Thermo gravimetric analysis } \\ \text { TOC } & \text { Total organic carbon } \\ \text { TPPs } & \text { Thermal power plants } \\ \text { UC } & \text { Unburned carbon } \\ \text { XPS } & \text { X-ray photoelectron spectroscopy }\end{array}$

\section{References}

1. Yadav, V.K.; Fulekar, M.H. Advances in Methods for Recovery of Ferrous, Alumina, and Silica Nanoparticles from Fly Ash Waste. Ceramics 2020, 3, 384-420. [CrossRef]

2. Vassilev, S.; Menendez, R.; Alvarez, D.; Díaz-Somoano, M.; Martínez-Tarazona, M. Phase-Mineral and Chemical Composition of Coal Fly Ashes as a Basis for Their Multicomponent Utilization. 1. Characterization of Feed Coals and Fly Ashes. Fuel 2003, 82, 1793-1811. [CrossRef]

3. Vassilev, S.; Menendez, R.; Borrego, A.; Díaz-Somoano, M.; Martínez-Tarazona, M. Phase-mineral and chemical composition of coal fly ashes as a basis for their multicomponent utilization. 3. Characterization of magnetic and char concentrates. Fuel 2004, 83, 1563-1583. [CrossRef]

4. Yadav, V.K.; Pandita, P.R. Fly Ash Properties and Their Applications as a Soil Ameliorant. In Amelioration Technology for Soil Sustainability; Rathoure, A.K., Ed.; IGI Global: Hershey, PA, USA, 2019; pp. 59-89. [CrossRef]

5. Pacewska, B.; Wilińska, I. Usage of supplementary cementitious materials: Advantages and limitations. J. Therm. Anal. Calorim. 2020, 142, 371-393. [CrossRef]

6. Nicoara, A.I.; Stoica, A.E.; Vrabec, M.; Smuc Rogan, N.; Sturm, S.; Ow-Yang, C.; Gulgun, M.A.; Bundur, Z.B.; Ciuca, I.; Vasile, B.S. End-of-Life Materials Used as Supplementary Cementitious Materials in the Concrete Industry. Materials 2020, 13, 1954. [CrossRef]

7. Fuller, A.; Maier, J.; Karampinis, E.; Kalivodova, J.; Grammelis, P.; Kakaras, E.; Scheffknecht, G. Fly Ash Formation and Characteristics from (co-)Combustion of an Herbaceous Biomass and a Greek Lignite (Low-Rank Coal) in a Pulverized Fuel Pilot-Scale Test Facility. Energies 2018, 11, 1581. [CrossRef]

8. Bhatt, A.; Priyadarshini, S.; Acharath Mohanakrishnan, A.; Abri, A.; Sattler, M.; Techapaphawit, S. Physical, chemical, and geotechnical properties of coal fly ash: A global review. Case Stud. Constr. Mater. 2019, 11, e00263. [CrossRef]

9. Yadav, V.K.; Saxena, P.; Lal, C.; Gnanamoorthy, G.; Choudhary, N.; Singh, B.; Tavker, N.; Kalasariya, H.; Kumar, P. Synthesis and Characterization of Mullites From Silicoaluminous Fly Ash Waste. Int. J. Appl. Nanotechnol. Res. (IJANR) 2021, 5, 18. [CrossRef]

10. Behera, A.; Mohapatra, S. Challenges in Recovery of Valuable and Hazardous Elements from Bulk Fly Ash and Options for Increasing Fly Ash Utilization. In Coal Fly Ash Beneficiation-Treatment of Acid Mine Drainage with Coal Fly Ash; Gitari, S.A.A.a.M.W., Ed.; Intechopen: London, UK, 2018. [CrossRef]

11. Chand Malav, L.; Yadav, K.K.; Gupta, N.; Kumar, S.; Sharma, G.K.; Krishnan, S.; Rezania, S.; Kamyab, H.; Pham, Q.B.; Yadav, S.; et al. A review on municipal solid waste as a renewable source for waste-to-energy project in India: Current practices, challenges, and future opportunities. J. Clean. Prod. 2020, 277, 123227. [CrossRef]

12. Yadav, V.K.; Fulekar, M.H. The current scenario of thermal power plants and fly ash: Production and utilization with a focus in India. Int. J. Adv. Eng. Res. Dev. 2018, 5, 768-777.

13. Tarafdar, A.; Sinha, A. Polycyclic Aromatic Hydrocarbons (PAHs) Pollution Generated from Coal-Fired Thermal Power Plants: Formation Mechanism, Characterization, and Profiling: Characterization and Control. In Pollutants from Energy Sources, Energy, Environment, and Sustainability; Agarwal, R.A.A., Gupta, T., Sharma, N., Eds.; Springer: Singapore, 2019; pp. 73-90. [CrossRef]

14. Cabral-Pinto, M.M.S.; Inácio, M.; Neves, O.; Almeida, A.A.; Pinto, E.; Oliveiros, B.; Ferreira da Silva, E.A. Human Health Risk Assessment Due to Agricultural Activities and Crop Consumption in the Surroundings of an Industrial Area. Exp. Health 2020, 12, 629-640. [CrossRef]

15. Hower, J.; Groppo, J.; Graham, U.; Ward, C.; Kostova, I.; Maroto-Valer, M.; Dai, S. Coal-derived unburned carbons in fly ash: A review. Int. J. Coal Geol. 2017, 179, 11-27. [CrossRef]

16. Yao, Z.; Ji, X.S.; Sarker, P.; Tang, J.H.; Ge, L.Q.; Xia, M.S.; Xi, Y.Q. A comprehensive review on the applications of coal fly ash. Earth Sci. Rev. 2015, 141, 105-121. [CrossRef]

17. Bayda, S.; Adeel, M.; Tuccinardi, T.; Cordani, M.; Rizzolio, F. The History of Nanoscience and Nanotechnology: From ChemicalPhysical Applications to Nanomedicine. Molecules 2020, 25, 112. [CrossRef] [PubMed]

18. Tavker, N.; Yadav, V.K.; Yadav, K.K.; Cabral-Pinto, M.M.S.; Alam, J.; Shukla, A.K.; Ali, F.A.A.; Alhoshan, M. Removal of Cadmium and Chromium by Mixture of Silver Nanoparticles and Nano-Fibrillated Cellulose Isolated from Waste Peels of Citrus Sinensis. Polymers 2021, 13, 234. [CrossRef] [PubMed]

19. Aqel, A.; El-Nour, K.M.M.A.; Ammar, R.A.A.; Al-Warthan, A. Carbon nanotubes, science and technology part (I) structure, synthesis and characterisation. Arab. J. Chem. 2012, 5, 1-23. [CrossRef]

20. Jovic, D.; Jacevic, V.; Kuca, K.; Borisev, I.; Mrdjanovic, J.; Petrovic, D.; Seke, M.; Djordjevic, A. The Puzzling Potential of Carbon Nanomaterials: General Properties, Application, and Toxicity. Nanomaterials 2020, 10, 1508. [CrossRef] 
21. Alarifi, I.M.; Khan, W.S.; Asmatulu, R. Synthesis of electrospun polyacrylonitrile-derived carbon fibers and comparison of properties with bulk form. PLOS ONE 2018, 13, e0201345. [CrossRef]

22. Wang, Z.; Chen, J.; Yang, P.; Qiao, X.; Tian, F. Polycyclic aromatic hydrocarbons in Dalian soils: Distribution and toxicity assessment. J. Environ. Monit. 9, 199-204. [CrossRef]

23. Kour, R.; Arya, S.; Young, S.-J.; Gupta, V.; Bandhoria, P.; Khosla, A. Review-Recent Advances in Carbon Nanomaterials as Electrochemical Biosensors. J. Electrochem. Soc. 2020, 167, 24. [CrossRef]

24. Moon, M.-W.; Kim, H.-Y.; Wang, A.; Vaziri, A. Nanostructured Carbon Materials. J. Nanomater. 2015, 2015, 916834. [CrossRef]

25. Wildgoose, G.; Banks, C.; Compton, R. Metal Nanoparticles and Related Materials Supported on Carbon Nanotubes: Methods and Applications. Small 2006, 2, 182-193. [CrossRef] [PubMed]

26. Abdel-Shafy, H.I.; Mansour, M.S.M. A review on polycyclic aromatic hydrocarbons: Source, environmental impact, effect on human health and remediation. Egypt. J. Pet. 2016, 25, 107-123. [CrossRef]

27. Fetzer, J. The Chemistry and Analysis of the Large Polycyclic Aromatic Hydrocarbons. Polycycl. Aromat. Compd. (New York: Wiley) 2000, 27, 143-147. [CrossRef]

28. Liu, G.; Niu, Z.; Van Niekerk, D.; Xue, J.; Zheng, L. Polycyclic Aromatic Hydrocarbons (PAHs) from Coal Combustion: Emissions, Analysis, and Toxicology. Rev. Environ. Contam. Toxicol. 2008, 192, 1-28. [CrossRef]

29. Liu, D.; Duan, Y.Y.; Yang, Z.; Yu, H.T. A new route for unburned carbon concentration measurements eliminating mineral content and coal rank effects. Sci. Rep. 2014, 4, 4567. [CrossRef]

30. Ohenoja, K.; Pesonen, J.; Yliniemi, J.; Illikainen, M. Utilization of Fly Ashes from Fluidized Bed Combustion: A Review. Sustainability 2020, 12, 2988. [CrossRef]

31. Salah, N.; Al-Ghamdi, A.; Memic, A.; Habib, S.; Khan, Z. Formation of Carbon Nanotubes from Carbon Rich Fly Ash: Growth Parameters and Mechanism. Mater. Manuf. Process. 2015, 31, 150811005209005. [CrossRef]

32. Hsieh, Y.-M.; Tsai, M.-S. Physical and chemical analyses of unburned carbon from oil-fired fly ash. Carbon 2003, 41, 2317-2324. [CrossRef]

33. Algarni, A.; Salah, N.; Bourchak, M.; Jilani, A.; Alshahrie, A.; Nahas, M.N. Polymer composite reinforced with nanoparticles produced from graphitic carbon-rich fly ash. J. Compos. Mater. 2016, 51, 2675-2685. [CrossRef]

34. Mofarrah, A.; Husain, T. Use of Heavy Oil Fly Ash as a Color Ingredient in Cement Mortar. Int. J. Concr. Struct. Mater. 2013, 7, 111-117. [CrossRef]

35. Singh, M.K.; Kumar, S.; Ratha, D. Physiochemical and leaching characteristics of fly and bottom ash. Energy Sources Part A Recovery Util. Environ. Eff. 2016, 38, 2377-2382. [CrossRef]

36. IEA. World Energy Outlook 2017; IEA: France, Paris, 2017.

37. Miricioiu, M.G.; Niculescu, V.C. Fly Ash, from Recycling to Potential Raw Material for Mesoporous Silica Synthesis. Nanomaterials 2020, 10, 474. [CrossRef] [PubMed]

38. Bartoňová, L. Unburned carbon from coal combustion ash: An overview. Fuel Process. Technol. 2015, 134, 136-158. [CrossRef]

39. Wilcox, J.; Wang, B.; Rupp, E.; Taggart, R.; Hsu-Kim, H.; Oliveira, M.; Cutruneo, C.; Taffarel, S.; Silva, L.; Hopps, S.; et al. Observations and Assessment of Fly Ashes from High-Sulfur Bituminous Coals and Blends of High-Sulfur Bituminous and Subbituminous Coals: Environmental Processes Recorded at the Macro- and Nanometer Scale. Energy Fuels 2015, 29, 7168-7177. [CrossRef]

40. Lewandowski, W.M.; Ryms, M.; Kosakowski, W. Thermal Biomass Conversion: A Review. Processes 2020, 8, 516. [CrossRef]

41. Saptoro, A.; Tade, M.O. Prediction and Monitoring of Unburnt Carbon in Fly Ash in Coal-Fired Power Plant; Curtin University of Technology: Perth, Australia, 2006.

42. Boycheva, S.; Zgureva, D.; Lazarova, K.; Babeva, T.; Popov, C.; Lazarova, H.; Popova, M. Progress in the Utilization of Coal Fly Ash by Conversion to Zeolites with Green Energy Applications. Materials 2020, 13, 2014. [CrossRef]

43. Sequeira, M.D.; Castilho, A.M.; Dinis, P.A.; Tavares, A.O. Impact Assessment and Geochemical Background Analysis of Surface Water Quality of Catchments Affected by the 2017 Portugal Wildfires. Water 2020, 12, 2742. [CrossRef]

44. Pinto, M.M.S.C.; Silva, E.A.F.d.; Silva, M.M.V.G.; Melo-Gonçalves, P.; Candeias, C. Environmental Risk Assessment Based on High-Resolution Spatial Maps of Potentially Toxic Elements Sampled on Stream Sediments of Santiago, Cape Verde. Geosciences 2014, 4, 297-315. [CrossRef]

45. Xue, J.; Liu, G.; Niu, Z.; Chou, C.-L.; Qi, C.; Zheng, L.; Zhang, H. Factors That Influence the Extraction of Polycyclic Aromatic Hydrocarbons from Coal. Energy Fuels 2007, 21, 881-890. [CrossRef]

46. Wang, R.; Liu, G.; Zhang, J.; Chou, C.L.; Liu, J. Abundances of polycyclic aromatic hydrocarbons (PAHs) in 14 chinese and american coals and their relation to coal rank and weathering. Energy Fuels 2010, 24, 6061-6066. [CrossRef]

47. Wei, X.-Y.; Gui, J.; Wang, Y.; Li, P.; Zong, Z.-M. Characterization of Biomarkers and Structural Features of Condensed Aromatics in Xianfeng Lignite. Energy Fuels 2013, 27, 7369-7378. [CrossRef]

48. Bowman, D.T.; Jobst, K.J.; Helm, P.A.; Kleywegt, S.; Diamond, M.L. Characterization of Polycyclic Aromatic Compounds in Commercial Pavement Sealcoat Products for Enhanced Source Apportionment. Environ. Sci. Technol. 2019, 53, $3157-3165$. [CrossRef] [PubMed]

49. Achten, C.; Hofmann, T. Native polycyclic aromatic hydrocarbons (PAH) in coals-A hardly recognized source of environmental contamination. Sci. Total Environ. 2009, 407, 2461-2473. [CrossRef] 
50. Jiao, H.; Wang, Q.; Zhao, N.; Jin, B.; Zhuang, X.; Bai, Z. Distributions and Sources of Polycyclic Aromatic Hydrocarbons (PAHs) in Soils around a Chemical Plant in Shanxi, China. Int. J. Environ. Res Public Health 2017, 14, 1198. [CrossRef]

51. Gerardo, B.; Cabral Pinto, M.; Nogueira, J.; Pinto, P.; Almeida, A.; Pinto, E.; Reis, A.; Diniz, L.; Moreira, P.; Simões, M.; et al. Associations between Trace Elements and Cognitive Decline: An Exploratory 5-Year Follow-Up Study of an Elderly Cohort. Int. J. Environ. Res Public Health 2020, 17, 6051. [CrossRef]

52. Liu, K.; Heltsley, R.; Zou, D.; Pan, W.-P.; Riley, J.T. Polyaromatic Hydrocarbon Emissions in Fly Ashes from an Atmospheric Fluidized Bed Combustor Using Thermal Extraction Coupled with GC/TOF-MS. Energy Fuels 2002, 16, 330-337. [CrossRef]

53. Alterary, S.; Marei, N.H. The Impact of Coal Fly Ash Purification on Its Antibacterial Activity. Minerals 2020, 10, 1002. [CrossRef]

54. Chen, H.-J.; Shih, N.-H.; Wu, C.-H.; Lin, S.-K. Effects of the Loss on Ignition of Fly Ash on the Properties of High-Volume Fly Ash Concrete. Sustainability 2019, 11, 2704. [CrossRef]

55. Golewski, G.L. Energy Savings Associated with the Use of Fly Ash and Nanoadditives in the Cement Composition. Energies 2020, 13, 2184. [CrossRef]

56. Fan, M.; Brown, R. Comparison of the Loss-on-Ignition and Thermogravimetric Analysis Techniques in Measuring Unburned Carbon in Coal Fly Ash. Fuel Energy Abstr. 2001, 43. [CrossRef]

57. Mohebbi, M.; Rajabipour, F.; Scheetz, B.E. Evaluation of Two-Atmosphere Thermogravimetric Analysis for Determining the Unburned Carbon Content in Fly Ash. Adv. Civ. Eng. Mater. 2017, 6, 258-279. [CrossRef]

58. Bartoéová, L.; Juchelková, D.; Klika, Z. On Unburned Carbon in Coal Ash from Various Combustion Units. Int. J. Mater. Metall. Eng. 2011, 5, 280-283.

59. Dai, S.; Zhao, L.; Peng, S.; Chou, C.L.; Wang, X.; Zhang, Y.; Li, D.; Sun, Y. Abundances and distribution of minerals and elements in high-alumina coal fly ash from the Jungar Power Plant, Inner Mongolia, China. Int. J. Coal Geol. 2010, 81, 320-332. [CrossRef]

60. Valeev, D.; Kunilova, I.; Alpatov, A.; Mikhailova, A.; Goldberg, M.; Kondratiev, A. Complex utilisation of ekibastuz brown coal fly ash: Iron \& carbon separation and aluminum extraction. J. Clean. Prod. 2019, 218, 192-201. [CrossRef]

61. Dinis, P.A.; Garzanti, E.; Hahn, A.; Vermeesch, P.; Cabral-Pinto, M. Weathering indices as climate proxies. A step forward based on Congo and SW African river muds. Earth Sci. Rev. 2020, 201. [CrossRef]

62. Lasagni, M.; Collina, E.; Ferri, M.; Tettamanti, M.; Pitea, D. Total Organic Carbon in Fly Ash from MSW Incinerators as a Potential Combustion Indicator: Setting Up of the Measurement Methodology and Preliminary Evaluation. Waste Manag. Res. 1997, 15, 507-521. [CrossRef]

63. Jara, A.D.; Betemariam, A.; Woldetinsae, G.; Kim, J.Y. Purification, application and current market trend of natural graphite: A review. Int. J. Min. Sci. Technol. 2019, 29, 671-689. [CrossRef]

64. Wei, G.; Liu, H.; Liu, F.; Zeng, T.; Liu, G.; Zhou, J. Experimental Investigation of the Decarburization Behavior of Medical Waste Incinerator Fly Ash (MWIFA). Processes 2018, 6, 186. [CrossRef]

65. Eisele, T.; Kawatra, S. Use of froth flotation to remove unburned carbon from fly ash. Miner. Process. Extr. Metall. Rev. 2002, 23, 1-10. [CrossRef]

66. Wrona, J.; Żukowski, W.; Bradło, D.; Czupryński, P. Recovery of Cenospheres and Fine Fraction from Coal Fly Ash by a Novel Dry Separation Method. Energies 2020, 13, 3576. [CrossRef]

67. Fraunholcz, N. Separation of waste plastics by froth flotation-A review, part I. Miner. Eng. 2004, 17, 261-268. [CrossRef]

68. Bournival, G.; Ata, S.; Jameson, G. Bubble and Froth Stabilizing Agents in Froth Flotation. Miner. Process. Extr. Metall. Rev. 2017, 38. [CrossRef]

69. Liaoa, Y.; Caoa, Y.; Hub, Z.; Taoc, X. A new preparation scheme for a difficult-to-float coking coal by column flotation following grinding. J. South. Afr. Inst. Min. Metall. 2015, 115, 161-164. [CrossRef]

70. Valeev, D.; Kunilova, I.; Alpatov, A.; Varnavskaya, A.; Ju, D. Magnetite and Carbon Extraction from Coal Fly Ash Using Magnetic Separation and Flotation Methods. Minerals 2019, 9, 320. [CrossRef]

71. Uçurum, M.; Toraman, Ö.Y.; Depci, T.; Yoğurtçuoğlu, E. A Study on Characterization and Use of Flotation to Separate Unburned Carbon in Bottom Ash from Çayirhan Power Plant. Energy Sources Part A Recovery Util. Environ. Eff. 2011, 33, 562-574. [CrossRef]

72. Das, A.; Sarkar, B.; Ari, V.; Roy, S. Efficient Recovery of Combustibles from Coking Coal Fines. Miner. Process. Extr. Metall. Rev. 2010, 31, 236-249. [CrossRef]

73. $\mathrm{Wu}, \mathrm{J} . ;$ Chen, L.; Zheng, N.; Sun, Z. Experimental investigation of the attachment of unburned carbon in coal fly ash to a stationary air bubble in aqueous solutions. Fuel 2021, 285, 119080. [CrossRef]

74. Gong, X.; Jiang, W.; Hu, S.; Yang, Z.; Liu, X.; Fan, Z. Comprehensive utilization of foundry dust: Coal powder and clay minerals separation by ultrasonic-assisted flotation. J Hazard Mater 2021, 402, 124124. [CrossRef]

75. Buha, J.; Mueller, N.; Nowack, B.; Ulrich, A.; Losert, S.; Wang, J. Physical and Chemical Characterization of Fly Ashes from Swiss Waste Incineration Plants and Determination of the Ash Fraction in the Nanometer Range. Environ. Sci. Technol. 2014, 48, 4765-4773. [CrossRef]

76. Xing, Y.; Guo, F.; Xu, M.; Gui, X.; Li, H.; Li, G.; Xia, Y.; Han, H. Separation of unburned carbon from coal fly ash: A review. Powder Technol. 2019, 353, 372-384. [CrossRef]

77. Rubio, B.; Izquierdo, M.T.; Mayoral, M.; Bona, M.T.; Martínez-Tarazona, M. Preparation and Characterisation of Carbon-Enriched Coal Fly Ash. J. Environ. Manag. 2008, 88, 1562-1570. [CrossRef] [PubMed]

78. Gray, M.L.; Champagne, K.J.; Soong, Y.; Finseth, D.H. Parametric study of the column oil agglomeration of fly ash. Fuel 2001, 80, 867-871. [CrossRef] 
79. Baltrus, J.P.; Wells, A.W.; Fauth, D.J.; Diehl, J.R.; White, C.M. Characterization of Carbon Concentrates from Coal-Combustion Fly Ash. Energy Fuels 2001, 15, 455-462. [CrossRef]

80. Nguyen, H.G.T.; Horn, J.C.; Bleakney, M.; Siderius, D.W.; Espinal, L. Understanding Material Characteristics through Signature Traits from Helium Pycnometry. Langmuir 2019, 35, 2115-2122. [CrossRef]

81. Bartoňová, L.; Čech, B.; Ruppenthalová, L.; Majvelderova, V.; Juchelková, D.; Klika, Z. Effect of unburned carbon content in fly ash on the retention of 12 elements out of coal-combustion flue gas. J. Environ. Sci. 2012, 24, 1624-1629. [CrossRef]

82. Li, G.; Deng, L.; Liu, J.; Cao, Y.; Zhang, H.; Ran, J. A New Technique for Removing Unburned Carbon From Coal Fly Ash at an Industrial Scale. Int. J. Coal Prep. Util. 2015, 35, 150527094541002. [CrossRef]

83. Gray, M.; Champagne, K.; Soong, Y.; Killmeyer, R.; Maroto-Valer, M.; Andresen, J.; Ciocco, M.; Zandhuis, P. Physical Cleaning of High Carbon Fly Ash. Fuel Process. Technol. 2002, 76, 11-21. [CrossRef]

84. Kim, J.-K.; Cho, H.-C.; Kim, S.-C. Removal of unburned carbon from coal fly ash using a pneumatic triboelectrostatic separator. J. Environ. Sci. Health Part A 2001, 36, 1709-1724. [CrossRef]

85. Wierzchowski, K.; Białecka, B.; Moszko, J.; Klupa, A. Characterization of unburned carbon separated from power plant slag. Int. J. Environ. Sci. Technol. 2020, 17, 2499-2510. [CrossRef]

86. Cabral Pinto, M.M.S.; Ferreira da Silva, E.A. Heavy Metals of Santiago Island (Cape Verde) Alluvial Deposits: Baseline Value Maps and Human Health Risk Assessment. Int. J. Environ. Res. Public Health 2019, 16, 2. [CrossRef] [PubMed]

87. Groppo, J.; Brooks, S.M. Froth flotation method for removing ultrafine carbon from fly ashes. Fuel Energy Abstr. 1996, $37,186$. [CrossRef]

88. Butcher, D.; Rowson, N. Electrostatic Separation of Pyrite from Coal. Magn. Electr. Sep. 1995, 6. [CrossRef]

89. Sahoo, P.K.; Kim, K.; Powell, M.A.; Equeenuddin, S.M. Recovery of metals and other beneficial products from coal fly ash: A sustainable approach for fly ash management. Int. J. Coal Sci. Technol. 2016, 3, 267-283. [CrossRef]

90. Soong, Y.; Schoffstall, M.R.; Gray, M.; Knoer, J.P.; Champagne, K.J.; Jones, R.J.; Fauth, D. Dry beneficiation of high loss-on-ignition fly ash. Sep. Purif. Technol. 2002, 26, 177-184. [CrossRef]

91. Cangialosi, F.; Notarnicola, M.; Liberti, L.; Stencel, J. The role of weathering on fly ash charge distribution during triboelectrostatic beneficiation. J. Hazard. Mater. 2008, 164, 683-688. [CrossRef] [PubMed]

92. Kumar, H.; Mohapatra, S.K.; Singh, R.I. Review on CFD Modelling of Fluidized Bed Combustion Systems based on Biomass and Co-firing. J. Inst. Eng. (India) Ser. C 2018, 99, 449-474. [CrossRef]

93. Zacharia, R.; Rather, S.U. Review of Solid State Hydrogen Storage Methods Adopting Different Kinds of Novel Materials. J. Nanomater. 2015, 2015, 914845. [CrossRef]

94. Ban, H.; Li, T.; Schaefer, J.L.; Stencel, J. Triboelectrostatic separation of unburned carbon from fly ash. Prepr. Pap. Am. Chem. Soc. Div. Fuel Chem. 1996, 41.

95. Maroto-Valer, M.; Zhang, Y.; Granite, E.; Tang, Z.; Pennline, H. Effect of porous structure and surface functionality on the mercury capacity of a fly ash carbon and its activated sample. Fuel 2005, 84, 105-108. [CrossRef]

96. Walker, A.; Wheelock, T. Separation of Carbon from Fly Ash Using Froth Flotation. Coal Prep. 2006, 26, 235-250. [CrossRef]

97. Hurt, R.; Davis, K.; Yang, N.; Headley, T.; Mitchell, G. Residual carbon from pulverized-coal-fired boilers. 2. Morphology and physicochemical properties. Fuel 1995, 74, 1297-1306. [CrossRef]

98. Li, J.; Zhou, L.; Li, P.; Jiajian, G.; Gu, F.; Su, F. Enhanced fluidized bed methanation over a Ni/Al2O3 catalyst for production of synthetic natural gas. Chem. Eng. J. 2013, 219, 183-189. [CrossRef]

99. Barnard, A.; Russo, S.; Snook, I. Coexistence of bucky diamond with nanodiamond and fullerene carbon phases. Phys. Rev. B 2003, 68. [CrossRef]

100. Francis, A.H. Electronic Structure Calculations on Fullerenes and Their Derivatives by Jerzy Cioslowski (Florida State University) Oxford University Press: New York. 1995. ix + 281 pp. \$65.00. ISBN 0-19-508806-9. J. Am. Chem. Soc. 1996, 118, 9458. [CrossRef]

101. Zaytseva, O.; Neumann, G. Carbon nanomaterials: Production, impact on plant development, agricultural and environmental applications. Chem. Biol. Technol. Agric. 2016, 3, 17. [CrossRef]

102. Dosodia, A.; Lal, C.; Singh, B.P.; Mathur, R.B.; Sharma, D. Development of Catalyst Free Carbon Nanotubes from Coal and Waste Plastics. Fuller. Nanotub. Carbon Nanostructures 2009, 17, 567-582. [CrossRef]

103. Gieré, R.; Blackford, M.; Smith, K. TEM Study of PM 2.5 Emitted from Coal and Tire Combustion in a Thermal Power Station. Environ. Sci. Technol. 2006, 40, 6235-6240. [CrossRef]

104. Tiwari, A.J.; Ashraf-Khorassani, M.; Marr, L.C. C 60 fullerenes from combustion of common fuels. Sci. Total Environ. 2016, 547, 254-260. [CrossRef]

105. Saikia, J.; Khare, P.; Saikia, P.; Saikia, B.K. Polycyclic aromatic hydrocarbons (PAHs) around tea processing industries using high-sulfur coals. Environ. Geochem. Health 2017, 39, 1101-1116. [CrossRef]

106. Martinello, K.; Hower, J.C.; Dotto, G.L.; Ramos, C.G.; Schnorr, C.E.; Pinto, D. Deposition of nanoparticles on school eyeglasses in urban and rural areas: A methodology for a more real assessment of the possible impacts. Geosci. Front. 2021. [CrossRef]

107. Konchits, A.A.; Shanina, B.D.; Krasnovyd, S.V.; Burya, A.I.; Kuznetsova, O.Y. Paramagnetic Properties of Fullerene-Derived Nanomaterials and Their Polymer Composites: Drastic Pumping Out Effect. Nanoscale Res. Lett. 2017, 12, 475. [CrossRef] [PubMed]

108. Hower, J.C.; Graham, U.M.; Dozier, A.; Tseng, M.T.; Khatri, R.A. Association of the Sites of Heavy Metals with Nanoscale Carbon in a Kentucky Electrostatic Precipitator Fly Ash. Environ. Sci. Technol. 2008, 42, 8471-8477. [CrossRef] [PubMed] 
109. Paul, K.T.; Satpathy, S.K.; Manna, I.; Chakraborty, K.K.; Nando, G.B. Preparation and Characterization of Nano structured Materials from Fly Ash: A Waste from Thermal Power Stations, by High Energy Ball Milling. Nanoscale Res. Lett. $2007,2,397$. [CrossRef]

110. Monthioux, M.; Kuznetsov, V. Who should be given the credit for the discovery of carbon nanotubes? Carbon 2006, 44, 1621-1623. [CrossRef]

111. Velasco-Santos, C.; Martínez-Hernández, A.; Cosultchi, A.; Rodríguez Talavera, J.R.; Castaño, V. Naturally produced carbon nanotubes. Chem. Phys. Lett. 2003, 373, 272-276. [CrossRef]

112. Alothman, Z.A.; Wabaidur, S.M. Application of carbon nanotubes in extraction and chromatographic analysis: A review. Arab. J. Chem. 2019, 12, 633-651. [CrossRef]

113. Alsharef, J.; Taha, M.; Khan, T. Physical dispersion of nanocarbons in composites-A review. J. Teknol. 2017, 79, 68-69. [CrossRef]

114. Batakliev, T.; Petrova-Doycheva, I.; Angelov, V.; Georgiev, V.; Ivanov, E.; Kotsilkova, R.; Casa, M.; Cirillo, C.; Adami, R.; Sarno, M.; et al. Effects of Graphene Nanoplatelets and Multiwall Carbon Nanotubes on the Structure and Mechanical Properties of Poly(lactic acid) Composites: A Comparative Study. Appl. Sci. 2019, 9, 469. [CrossRef]

115. Hatui, G.; Bhattacharya, P.; Sahoo, S.; Dhibar, S.; Das, C.K. Combined effect of expanded graphite and multiwall carbon nanotubes on the thermo mechanical, morphological as well as electrical conductivity of in situ bulk polymerized polystyrene composites. Compos. Part A Appl. Sci. Manuf. 2014, 56, 181-191. [CrossRef]

116. Venkataraman, A.; Amadi, E.V.; Chen, Y.; Papadopoulos, C. Carbon Nanotube Assembly and Integration for Applications. Nanoscale Res. Lett. 2019, 14, s019-s11671. [CrossRef] [PubMed]

117. Das, T.; Saikia, B.K.; Baruah, B.P. Formation of carbon nano-balls and carbon nano-tubes from northeast Indian Tertiary coal: Value added products from low grade coal. Gondwana Res. 2016, 31, 295-304. [CrossRef]

118. Oliveira, M.; Marostega, F.; Taffarel, S.; Saikia, B.K.; Waanders, F.; Martinello, K.; Baruah, B.P.; Silva, L. Nano-mineralogical investigation of coal and fly ashes from coal-based captive power plant (India): An introduction of occupational health hazards. Sci. Total Environ. 2013, 468-469C, 1128-1137. [CrossRef] [PubMed]

119. Hintsho, N.; Shaikjee, A.; Masenda, H.; Naidoo, D.; Billing, D.; Franklyn, P.; Durbach, S. Direct synthesis of carbon nanofibers from South African coal fly ash. Nanoscale Res. Lett. 2014, 9, 387. [CrossRef]

120. Kronbauer, M.; Izquierdo, M.; Dai, S.; Waanders, F.; Wagner, N.; Mastalerz, M.; Hower, J.; Oliveira, M.; Taffarel, S.; Bizani, D.; et al. Geochemistry of ultra-fine and nano-compounds in coal gasification ashes: A synoptic view. Sci. Total Environ. 2013, 456-457C, 95-103. [CrossRef]

121. Martinello, K.; Oliveira, M.; Molossi, F.; Ramos, C.; Calesso Teixeira, E.; Kautzmann, R.; Silva, L. Direct identification of hazardous elements in ultra-fine and nanominerals from coal fly ash produced during diesel co-firing. Sci. Total Environ. 2013, 470-471C, 444-452. [CrossRef]

122. Silva, L.; Martinello, K.; Mardon, S.; Hower, J.; Serra-Rodríguez, C. Fullerenes and Metallofullerenes in Coal-Fired Stoker Fly Ash. Coal Combust. Gasif. Prod. 2010, 2. [CrossRef]

123. Eatemadi, A.; Daraee, H.; Karim Khanloo, H.; Kouhi, M.; Zarghami, N.; Akbarzadeh, A.; Abasi, M.; Hanifehpour, Y.; Joo, S. Carbon nanotubes: Properties, synthesis, purification, and medical applications. Nanoscale Res. Lett. 2014, 9. [CrossRef]

124. Shahidi, S.; Moazzenchi, B. Carbon nanotube and its applications in textile industry-A review. J. Text. Inst. 2018, 109, 1653-1666. [CrossRef]

125. Rajak, D.K.; Pagar, D.D.; Menezes, P.L.; Linul, E. Fiber-Reinforced Polymer Composites: Manufacturing, Properties, and Applications. Polymers (Basel) 2019, 11, 1667. [CrossRef]

126. Rauti, R.; Musto, M.; Bosi, S.; Prato, M.; Ballerini, L. Properties and behavior of carbon nanomaterials when interfacing neuronal cells: How far have we come? Carbon 2019, 143, 430-446. [CrossRef]

127. Coetzee, D.; Venkataraman, M.; Militky, J.; Petru, M. Influence of Nanoparticles on Thermal and Electrical Conductivity of Composites. Polymers (Basel) 2020, 12, 742. [CrossRef] [PubMed]

128. Trakakis, G.; Tomara, G.; Datsyuk, V.; Sygellou, L.; Bakolas, A.; Tasis, D.; Parthenios, J.; Krontiras, C.; Georga, S.; Galiotis, C.; et al. Mechanical, Electrical, and Thermal Properties of Carbon Nanotube Buckypapers/Epoxy Nanocomposites Produced by Oxidized and Epoxidized Nanotubes. Materials 2020, 13, 4308. [CrossRef] [PubMed]

129. Lan, Y.; Wang, Y.; Ren, Z. Physics and applications of aligned carbon nanotubes. Adv. Phys. 2011, 60, 553-678. [CrossRef]

130. Camilli, L.; Passacantando, M. Advances on Sensors Based on Carbon Nanotubes. Chemosensors 2018, 6, 62. [CrossRef]

131. Chen, J. Coal fly ash an amendment to container substrate for Spathiphyllum production. Bioresour. Technol. 2006, 97, 1920-1926. [CrossRef]

132. Chen, Y.; Shah, N.; Huggins, F.E.; Huffman, G.P. Transmission Electron Microscopy Investigation of Ultrafine Coal Fly Ash Particles. Environ. Sci. Technol. 2005, 39, 1144-1151. [CrossRef]

133. Murr, L.; Soto, K. A TEM study of soot, carbon nanotubes, and related fullerene nanopolyhedra in common fuel-gas combustion sources. Mater. Charact. 2005, 554, 50-65. [CrossRef]

134. Lou, L.; Luo, L.; Wang, W.; Xu, X.; Hou, J.; Xun, B.; Chen, Y. Impact of black carbon originated from fly ash and soot on the toxicity of pentachlorophenol in sediment. J. Hazard. Mater. 2011, 190, 474-479. [CrossRef]

135. Veranth, J.M.; Fletcher, T.H.; Pershing, D.W.; Sarofim, A.F. Measurement of soot and char in pulverized coal fly ash. Fuel 2000, 79, 1067-1075. [CrossRef] 
136. Chen, Z.; Ye, S.; Evans, S.; Ge, Y.; Zhu, Z.; Tu, Y.; Yang, X. Confined Assembly of Hollow Carbon Spheres in Carbonaceous Nanotube: A Spheres-in-Tube Carbon Nanostructure with Hierarchical Porosity for High-Performance Supercapacitor. Small 2018, 14, 1-8. [CrossRef]

137. Chen, Y.; Shah, N.; Huggins, F.E.; Huffman, G.P. Investigation of the Microcharacteristics of PM2.5 in Residual Oil Fly Ash by Analytical Transmission Electron Microscopy. Environ. Sci. Technol. 2004, 38, 6553-6560. [CrossRef] [PubMed]

138. Nicholls, R.; Sader, K.; Warner, J.; Plant, S.; Porfyrakis, K.; Nellist, P.; Briggs, G.; Cockayne, D. Direct Imaging and Chemical Identification of the Encapsulated Metal Atoms in Bimetallic Endofullerene Peapods. ACS Nano 2010, 4, 3943-3948. [CrossRef] [PubMed]

139. Gunture; Kaushik, J.; Garg, A.K.; Saini, D.; Khare, P.; Sonkar, S.K. Pollutant Diesel Soot Derived Onion-like Nanocarbons for the Adsorption of Organic Dyes and Environmental Assessment of Treated Wastewater. Ind. Eng. Chem. Res. 2020, 59, 12065-12074. [CrossRef]

140. Graham, U.; Dozier, A.; Khatri, R.; Tseng, M.; Hower, J.; Davis, B. Ultra-Fine PM Derived from Fullerene-Like Carbon in Electrostatic Precipitator Fly Ash. In Proceedings of the 2008 AIChE Annual Meeting, Philadelphia, PA, USA, 16-21 November 2008.

141. Everson, R.; Neomagus, H.; Kasaini, H.; Njapha, D. Reaction kinetics of pulverized coal-chars derived from inertinite-rich coal discards: Gasification with carbon dioxide and steam. Fuel 2006, 85, 1076-1082. [CrossRef]

142. Pedersen, K.H.; Jensen, A.; Skjøth-Rasmussen, M.; Dam-Johansen, K. A review of the interference of carbon containing fly ash with air entrainment in concrete. Prog. Energy Combust. Sci. 2008, 34, 135-154. [CrossRef]

143. Bralewska, K.; Rakowska, J. Concentrations of Particulate Matter and PM-Bound Polycyclic Aromatic Hydrocarbons Released during Combustion of Various Types of Materials and Possible Toxicological Potential of the Emissions: The Results of Preliminary Studies. Int. J. Environ. Res. Public Health 2020, 17, 3202. [CrossRef]

144. Ruwei, W.; Jiamei, Z.; Jingjing, L.; Liu, G. Levels and Patterns of Polycyclic Aromatic Hydrocarbons in Coal-Fired Power Plant Bottom Ash and Fly Ash from Huainan, China. Arch. Environ. Contam. Toxicol. 2013, 65, 193-202. [CrossRef]

145. Lima, A.; Farrington, J.; Reddy, C. Combustion-Derived Polycyclic Aromatic Hydrocarbons in the Environment-A Review. Environ. Forensics 2005, 6, 109-131. [CrossRef]

146. Kleinhans, U.; Wieland, C.; Frandsen, F.J.; Spliethoff, H. Ash formation and deposition in coal and biomass fired combustion systems: Progress and challenges in the field of ash particle sticking and rebound behavior. Prog. Energy Combust. Sci. 2018, 68, 65-168. [CrossRef]

147. Singh, S.; Kumar, V.; Romero, R.; Sharma, K.; Singh, J. Applications of Nanoparticles in Wastewater Treatment. In Nanobiotechnology in Bioformulations; Springer: Cham, Switzerland, 2019; pp. 395-418. [CrossRef]

148. Reizer, E.; Csizmadia, I.G.; Palotás, Á.B.; Viskolcz, B.; Fiser, B. Formation Mechanism of Benzo(a)pyrene: One of the Most Carcinogenic Polycyclic Aromatic Hydrocarbons (PAH). Molecules 2019, 24, 1040. [CrossRef] [PubMed]

149. Hirondart, M.; Rombaut, N.; Fabiano-Tixier, A.S.; Bily, A.; Chemat, F. Comparison between Pressurized Liquid Extraction and Conventional Soxhlet Extraction for Rosemary Antioxidants, Yield, Composition, and Environmental Footprint. Foods 2020, 9, 584. [CrossRef] [PubMed]

150. Hollender, J.; Koch, B.; Lutermann, C.; Dott, W. Efficiency of Different Methods and Solvents for the Extraction of Polycyclic Aromatic Hydrocarbons from Soils. Int. J. Environ. Anal. Chem. 2003, 83, 21-32. [CrossRef]

151. Adeniji, A.O.; Okoh, O.O.; Okoh, A.I. Analytical Methods for Polycyclic Aromatic Hydrocarbons and their Global Trend of Distribution in Water and Sediment: A Review. In Recent Insights in Petroleum Science and Engineering; Intech: London, UK, 2018. [CrossRef]

152. Akila, S.; Srinivasan, P. Production of Polyphenol from Phyllanthus Emblica using Soxhlet Extraction Process. Int. J. Recent Technol. Eng. 2019, 8, 5010-5012. [CrossRef]

153. Moret, S.; Conchione, C.; Srbinovska, A.; Lucci, P. Microwave-Based Technique for Fast and Reliable Extraction of Organic Contaminants from Food, with a Special Focus on Hydrocarbon Contaminants. Foods 2019, 8, 503. [CrossRef]

154. Haneef, T.; Mustafa, M.R.U.; Wan Yusof, K.; Isa, M.H.; Bashir, M.J.K.; Ahmad, M.; Zafar, M. Removal of Polycyclic Aromatic Hydrocarbons (PAHs) from Produced Water by Ferrate (VI) Oxidation. Water 2020, 12, 3132. [CrossRef]

155. Yang, L.; Wu, J.; Zheng, M.; Cao, Z.; Li, C.; Shi, M.; Liu, G. Non-target screening of organic pollutants and target analysis of halogenated polycyclic aromatic hydrocarbons in the atmosphere around metallurgical plants by high-resolution GC/Q-TOF-MS. Environ. Sci. Eur. 2020, 32, 96. [CrossRef]

156. Mastral, A.; Garcia, T.; Callén, M.; Lopez, J.; Murillo, R.; Navarro, M. Effects of Limestone on Polycyclic Aromatic Hydrocarbon Emissions during Coal Atmospheric Fluidized Bed Combustion. Energy Fuels 2001, 15, 1469-1474. [CrossRef]

157. Adeniji, A.O.; Okoh, O.O.; Okoh, A.I. Levels of Polycyclic Aromatic Hydrocarbons in the Water and Sediment of Buffalo River Estuary, South Africa and Their Health Risk Assessment. Arch. Environ. Contam. Toxicol. 2019, 76, 657-669. [CrossRef]

158. Honda, M.; Suzuki, N. Toxicities of Polycyclic Aromatic Hydrocarbons for Aquatic Animals. Int. J. Environ. Res. Public Health 2020, 17, 1363. [CrossRef]

159. Clack, H.L. Estimates of Increased Black Carbon Emissions from Electrostatic Precipitators during Powdered Activated Carbon Injection for Mercury Emissions Control. Environ. Sci. Technol. 2012, 46, 7327-7333. [CrossRef] [PubMed]

160. Baby, R.; Saifullah, B.; Hussein, M.Z. Carbon Nanomaterials for the Treatment of Heavy Metal-Contaminated Water and Environmental Remediation. Nanoscale Res. Lett. 2019, 14, 341. [CrossRef] [PubMed] 
161. Mandeep; Shukla, P. Microbial Nanotechnology for Bioremediation of Industrial Wastewater. Front Microbiol 2020, $11,590631$. [CrossRef] [PubMed]

162. Bianco, A.; Chen, Y.; Frackowiak, E.; Holzinger, M.; Koratkar, N.; Meunier, V.; Mikhailovsky, S.; Strano, M.; Tascon, J.; Terrones, M. Carbon Science Perspective in 2020: Current Research and Future Challenges. Carbon 2020, 161, 373-391. [CrossRef]

163. Gao, F.; Tang, X.; Yi, H.; Zhao, S.; Li, C.; Li, J.; Shi, Y.; Meng, X. A Review on Selective Catalytic Reduction of NOx by NH3 over Mn-Based Catalysts at Low Temperatures: Catalysts, Mechanisms, Kinetics and DFT Calculations. Catalysts 2017, 7, 199. [CrossRef]

164. Cao, W.; Zhang, W. Low temperature selective catalytic reduction of nitric oxide with an activated carbon-supported zero-valent iron catalyst. Rsc Adv. 2020, 10, 42613-42618. [CrossRef]

165. Assi, A.; Bilo, F.; Zanoletti, A.; Ponti, J.; Valsesia, A.; La Spina, R.; Depero, L.E.; Bontempi, E. Review of the Reuse Possibilities Concerning Ash Residues from Thermal Process in a Medium-Sized Urban System in Northern Italy. Sustainability 2020, 12, 4193. [CrossRef]

166. Badenhorst, C.; Santos, C.; Lázaro-Martínez, J.; Białecka, B.; Cruceru, M.; Guedes, A.; Guimarães, R.; Moreira, K.; Predeanu, G.; Suárez-Ruíz, I.; et al. Assessment of Graphitized Coal Ash Char Concentrates as a Potential Synthetic Graphite Source. Minerals 2020, 10, 986. [CrossRef]

167. Ge, J.C.; Yoon, S.; Choi, N. Application of Fly Ash as an Adsorbent for Removal of Air and Water Pollutants. Appl. Sci. 2018, 8, 1116. [CrossRef]

168. Pransisco, P.; Singh, M.S.; Shuaib, M.; Shukur, M.F.; Joseph, E. 3D graphene/fly ash waste material for hybrid supercapacitor electrode: Specific capacitance analysis. Mater. Und Werkst. 2020, 51, 713-718. [CrossRef]

169. Abdelbasir, S.M.; McCourt, K.M.; Lee, C.M.; Vanegas, D.C. Waste-Derived Nanoparticles: Synthesis Approaches, Environmental Applications, and Sustainability Considerations. Front. Chem. 2020, 8, 782. [CrossRef] [PubMed]

170. Ong, Y.T.; Ahmad, A.L.; Zein, S.H.S.; Tan, S.H. A review on carbon nanotubes in an environmental protection and green engineering perspective. Braz. J. Chem. Eng. 2010, 27, 227-242. [CrossRef] 